Bull. Geol. Soc. Finland 41, 203-229 (1969)

\title{
MORPHOLOGISCH-STRATIGRAPHISCHE GRUNDZÜGE DES ÖSTLICHEN SALPAUSSELKÄ-GEBIETS
}

\author{
Reino Repo und Risto Tynni \\ Geologische Forschungsanstalt in Finnland, Otaniemi, Finnland
}

\begin{abstract}
The present study is concerned with some aspects of the Quaternary history of the eastern parts of the Salpausselkä region. The most prominent features of the Salpausselkä marginal formation are the glaciofluvial deltas and the hill and kettle topography in the high proximal parts. Till layers have been found on top of sorted material in some of the sections through the proximal parts. Oscillation of the ice margin has lefts marks also in the terrain between the Salpausselkäs. The orientation and distribution of glaciofluvial formations, and especially of eskers has been to a large extent governed by bedrock tectonics.

The oldest organic sediments from two bogs have been dated. According to $\mathrm{C}^{14}$ determinations the Koivusilta bog basin, between the First and Second Salpausselkä, was occupied by a lake $8250 \pm 300$ yrs B.C. corresponding to the end of the Younger Dryas-period. Fine sand containing Bryales- peat was deposited $8150 \pm 400 \mathrm{yrs}$ B.C. in a bog pond in Eräjärvi 2 kilometers north of the 2nd. Salpausselkä. The decrease in organic content after this period was observed in three core samples, being probably due to the deterioration of the climate during the transition from the Younger Dryas to the Preboreal period. It corresponds to the Preboreal climatic deterioration in Central European zonation.
\end{abstract}

\section{INHALT}

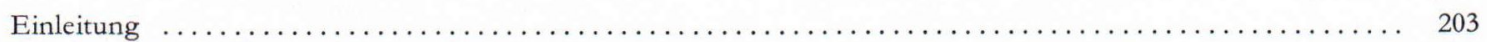

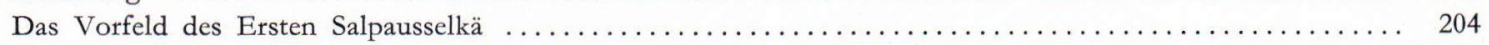

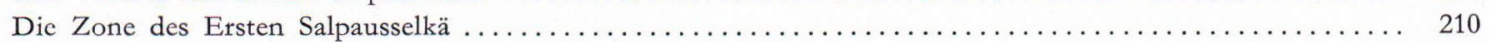

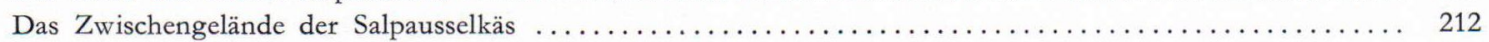

Die Entwicklung im Licht der Pollen- und Diatomeenuntersuchungen . . . . . . . . . . . . . . . . . 216

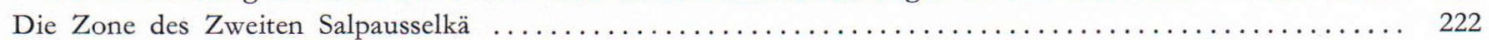

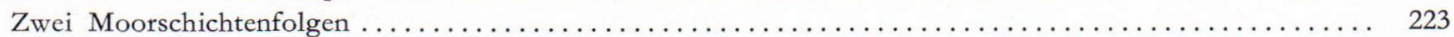

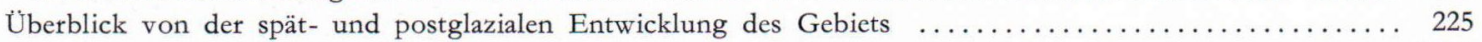

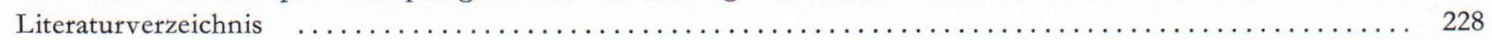

\section{Einleitung}

Die vorliegende Untersuchung befasst sich mit dem Gebiet von Imatra-Parikkala_Kitee und ist die Fortsetzung zur unserer früheren Untersuchung über das im Nordosten angrenzende Gebiet von Nordkarelien (Repo und Tynni 1967). In beiden Arbeiten nehmen die Salpaus- 
selkäs eine zentrale Stellung ein. In den letzten Jahren sind in den Salpausselkäs neue Bodenaufschlüsse angelegt worden, an denen die Struktur zu erkennen ist. Ausserdem können manche bedeutsame Beobachtungen an den Aufschlüssen der glazifluvialen Aufschüttungen im Zwischengelände der Salpausselkäs gemacht werden. Ferner spielt die Untersuchung der Vegetationsgeschichte älterer Verlandungen vor allem mit Hilfe der Pollenanalyse in unserer Arbeit eine zentrale Rolle.

Die neuere Erforschung der quartären Bildungen hat sich mit dem besagten Gebiet nicht so weitgehend befasst, dass sie ein einheitliches Bild von der Entwicklung geliefert hätte, abgesehen von Sauramos (1958) Beschreibung von Nordkarelien. Bedeutsame Beobachtungen sind in letzter Zeit u.a. am Ersten Salpausselkä in Imatra und Rautjärvi gemacht worden, wo in der jüngeren Dryaszeit entstandene Eiskeile festgestellt worden sind (Donner, Lappalainen, West 1968).

Die Gewässer des Gebiets fliessen in den Ladogasee, von welchem der kürzeste Abstand nur $25 \mathrm{~km}$ beträgt. Nach der von Hyyppä (1966) veröffentlichten paläographischen Karte hat sich das postglaziale Yoldiameer nicht bis zum Ladogasee erstreckt. Nach Sauramo (1958) wiederum hätte das Yoldiameer bis an den Ladogasee herangereicht und damit auch in das Untersuchungsgebiet ins Vorfeld des Salpausselkä auf den Isobasen von ca. $50 \mathrm{~m}$. Zwischen den Salpausselkäs und nördlich von ihnen bildete das Yoldiameer schmale Buchten (Sauramo, op.cit. S. 410). Dementsprechend wäre es garnicht verwunderlich, wenn die Diatomeenanalysen des Yoldiameers in dem Gebiet Süsswasser anzeigen würden. Der Ladogasee hat sich auch nicht getrennt in das Untersuchungsgebiet erstreckt, wo die tiefsten Stellen u.a. in Lahnasennurmi, Änkilä, in ca. 47 m Höhe liegen. Nach Hyyppä (1937) ist nördlich vom Ladogasee in Kirjavalahti die Höhe der auf das beginnende Subatlantikum datierten Ladogatransgression ca. 22.4-23.7 m ü.d.M.

Der Gross-Saimaa (Hellaakoski 1922) er- streckte sich nach Sauramos ergänzender Darstellung u.a. in die Zone zwischen dem 1. und 2. Salpausselkä im Niveau von ca. $80 \mathrm{~m}$, was etwa $4 \mathrm{~m}$ höher ist als der heutige Wasserspiegel des Saimaa-Sees.

Gewisse spätglaziale Uferverschiebungsvorgänge sind in dem Gebiet von den Bewegungen des Inlandeises und der Lage des Eisrandes abhängig gewesen. Die in Abb. 1 wiedergegebenen Schrammen aus dem Untersuchungsgebiet haben wir in der Veröffentlichung von Berghell (1904) gesammelt sowie zu einem beträchtlichen Teil noch durch unsere neuen Beobachtungen ergänzt. Die beobachteten Schrammenrichtungen sind im Vergleich zu dem östlichen Gebiet (Repo und Tynni 1967) relativ einheitlich und repräsentieren eine mehr nordwestliche Ausgangsrichtung und verlaufen durchschnittlich senkrecht zum Bogen des Salpausselkä. Das Zurückweichen des Eisrandes ist in diesem $\mathrm{Ge}$ biet wahrscheinlich uneinheitlich und durch Oszillationen unterbrochen abgelaufen. Hierauf weisen u.s. manche an glazifluviale Ablagerungen anschliessende Moränendecken hin.

Aus Abb. 2 ist die Lage der untersuchten Schichtenfolgen und der wichtigsten Beobachtungsstellen ersichtlich.

\section{Das Vorfeld des Ersten Salpausselkä}

Der finnische Teil umfasst einen ca. $40 \mathrm{~km}$ langen und ein paar $\mathrm{km}$ breiten Streifen, der sich von Imatra bis zum Westteil von Parikkala erstreckt. Kennzeichnend für die Landschaft Südost-Finnlands sind die von einem starken Bruchspaltensystem und von der Erosion im kristallinischen Felsgrund geschaffenen Senken und die dazwischenliegenden Erhebungen. Innerhalb der Salpausselkäs unterscheiden die Bruchtäler sich oft als Seen, aber im Vorfeld liegen die Sedimente der Becken im allgemeinen bloss, weil die tiefer gelegenen Senken als Flusstäler zum Ladogasee hin abfallen. Durchschnittlich liegt der Erste Salpausselkä an der Grenzlinie 


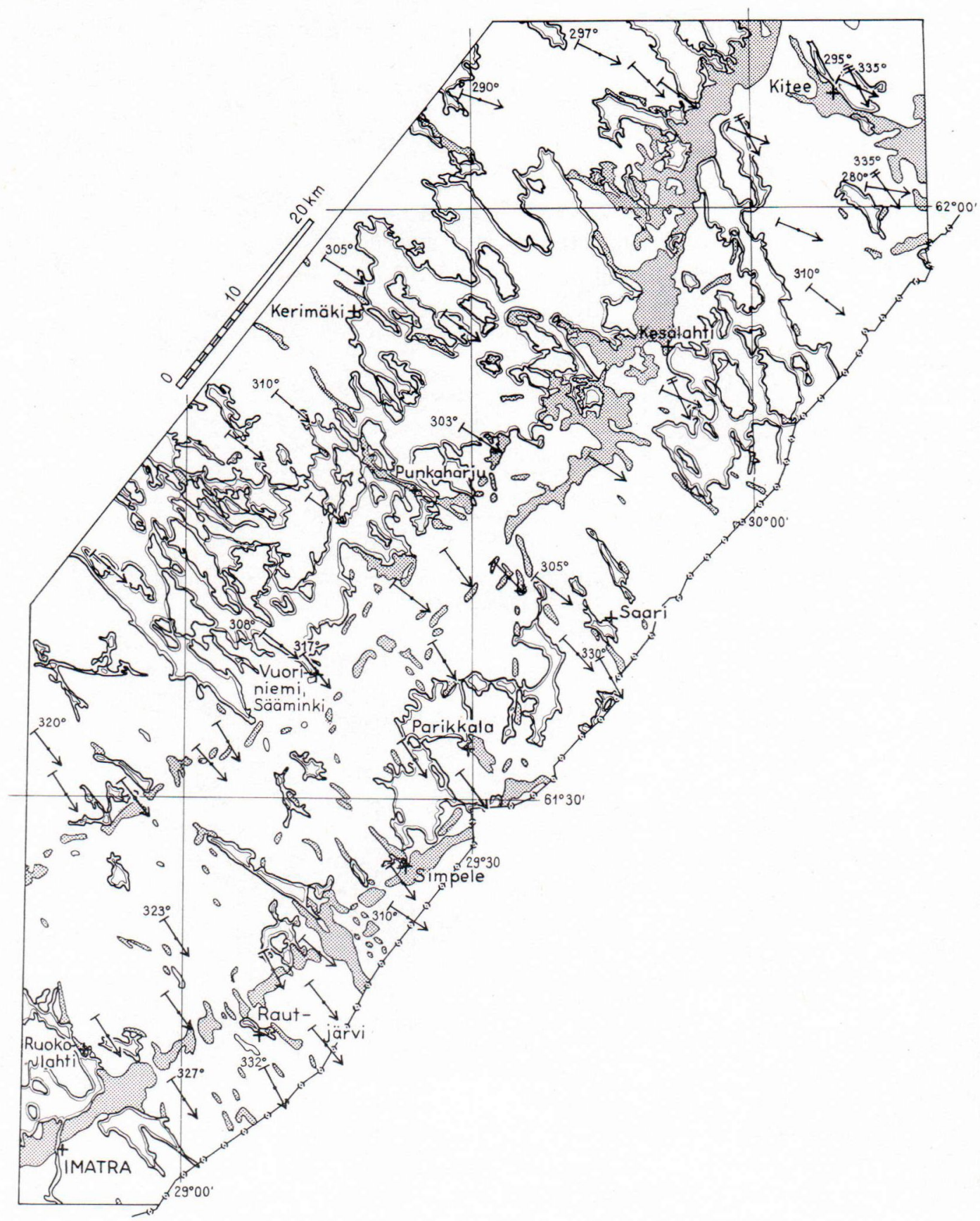

Abb. 1. Die Salpausselkäs und anderen glazifluvialen Aufschüttungen (punktiert) sowie Schrammenbeobachtungen (Pfeile: ein Querstrich = jüngste, zwei Querstriche = ältere Schrammentichtung an dem Beobachtungspunkt). 


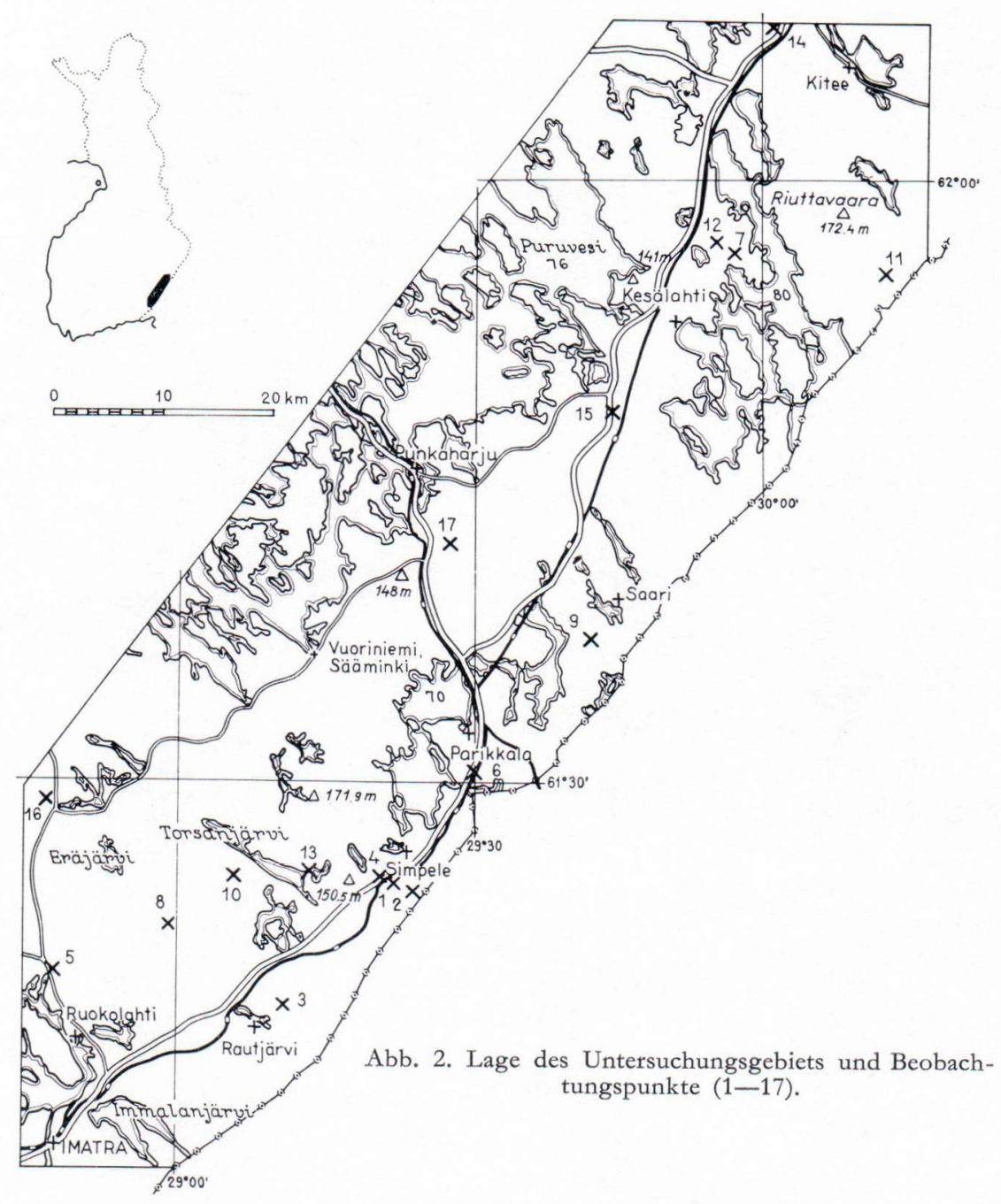

zwischen dem südostwärts geneigten Vorfeld und dem höheren Gebiet mit ebenerem Untergrund. Leiviskä (1920) hat nachdrücklich auf die Bedeutung der Höhenverhältnisse des Untergrundes für die Entstehung der Salpausselkäs überhaupt hingewiesen, und im Besonderen an den grossen Becken, wo die Salpausselkäs ihre grössten Dimensionen erreichen.

Die höchsten Stellen des Vorfeldes liegen 141 -144 m ü.d.M. In der Hauptsache sind es kahle Felsen, aber stellenweise sind sie auch von Moräne bedeckt. Der tiefste Geländepunkt ist das
Tal des Kokkolanjoki in Änkilä (46-50 m ü.d.M.). Der vom See Simpeleenjärvi abfliessende Kokkolanjoki durchbricht den Salpausselkä an einer relativ schmalen Stelle. Die Verlandung des niedrigsten Vorgeländes des Salpausselkä und die Entstehung des Betts des Kokkolanjoki beleuchten die vereinigten Pollen- und Diatomeendiagramme (Abb. 3 und 4) vom Moor Lahnasennurmi (Abb. 2, Punkt 1) und dem benachbarten Suomaa (Punkt 2). Aus dem ersteren geht hervor, dass im Niveau von Lahnasennurmi in der Jüngeren Dryaszeit gebänderter 
Pollen

Diatomaceae

Entwicklung

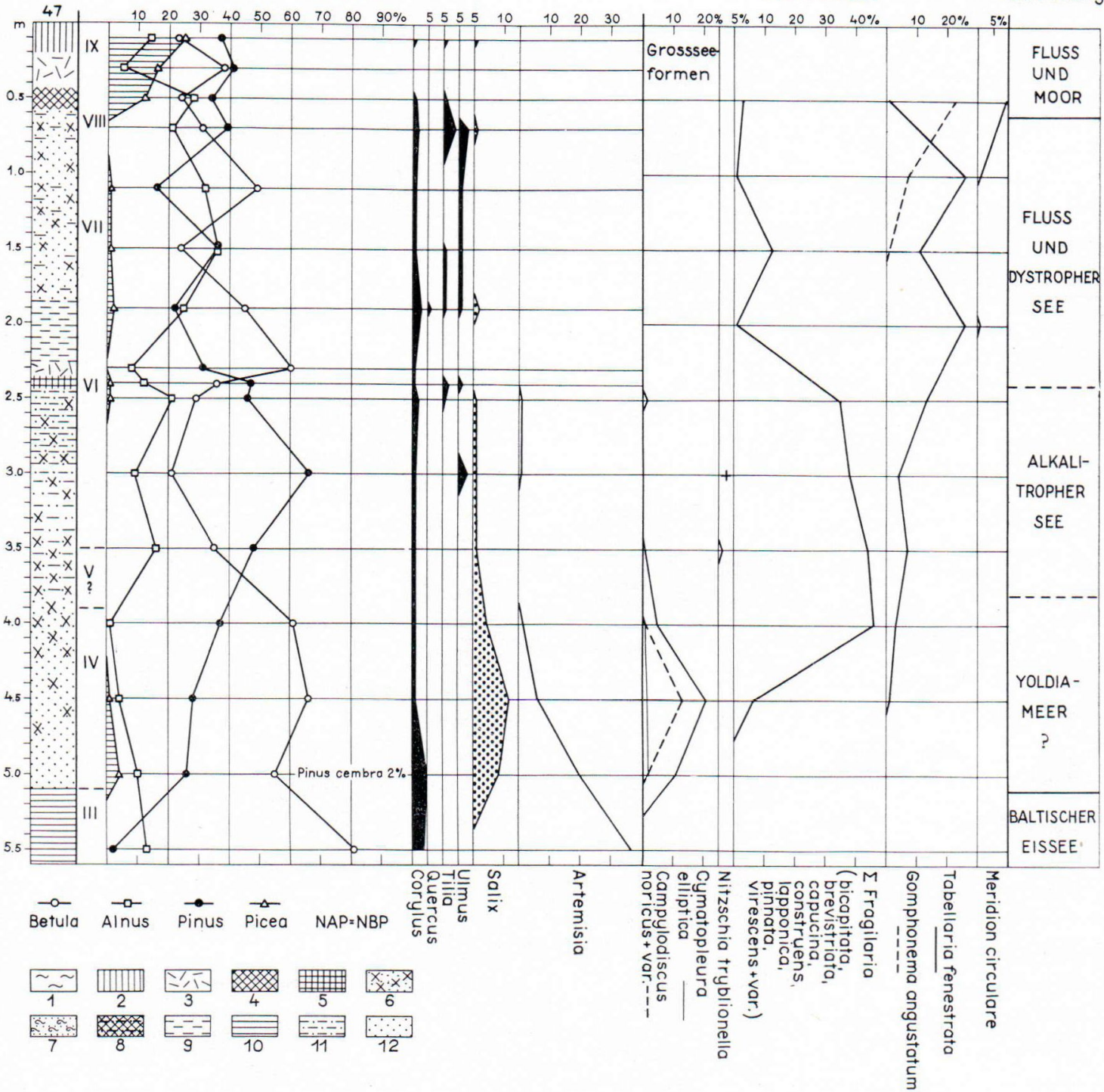

Abb. 3. Pollen- und Diatomeendiagramm von Lahnasennurmi.

1. Sphagnum-Torf, 2. Carex-Torf, 3. Akkumulationstorf, 4. Detritus-Gyttja, 5. Diatomeengyttja, 6. Gyttjahaltiger Feinsand, 7. Bryales-haltiger Feinsand, 8. Gyttjahaltiger Schluff, 9. Ton, 10. Bänderton, 11. Schluff, 12. Feinsand.

Schluff sedimentiert wurde, im Präboreal aber gyttjahaltiger Feinsand. Die präboreale Sedimentation hat wahrscheinlich am ehesten im Bereich des Ladogabeckens stattgefunden. Hiervon zeugen die Grossseeformen der Diatomeen, im ganzen $21 \%$. Die Diatomeen lassen in diesem Falle also keinen gleichzeitigen Zusammenhang zwischen dem Ladogasee und dem Yoldiameer erkennen. Auf eine schwache Verbindung zwischen dem leicht salzhaltigen Ostteil des Yoldiameers und dem Ladoga könnte vielleicht die Diatomeenflora der Bodensedimente in der Schichtenfolge von Suomaa hinweisen. Das Maximum bildet darin die Süss-Brackwasser- 


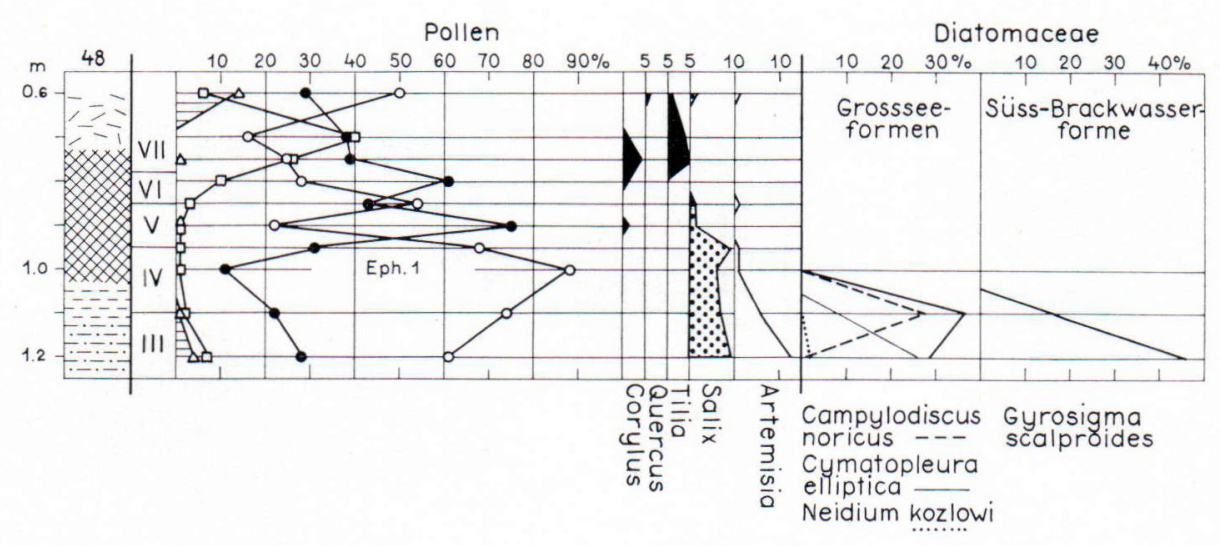

Abb. 4. Pollen- und Diatomeendiagramm von Suomaa.

form Gyrosigma scalproides, und die Grossseeformen machen $29 \%$ aus.

Das Becken von Lahnasennurmi und das flache, ton- und feinsandbedeckte Flusstal im Bereich von Suomaa sind vom Ladogabecken schon in der Präborealzeit abgeschnürt worden. Erst relativ spät vermoorten sie, u.a. Lahnasennurmi um die Wende vom Subboreal zum Atlantikum. Der Kokkolanjoki hat sich wahrscheinlich in der gleichen Zeit sein Bett gegraben, was sich im Erscheinen der Fliesswasserform Meridion circulare in der Diatomeenflora widerspiegelt. Das Seenstadium von Lahnasennurmi zerfällt in zwei Typen: Anfänglich bestand den Diatomeen gemäss ein alkalitropher See, dann ein seichteres, dystrophes Seenstadium. Zwischen diesen beiden Stadien lag eine kurze Trockenperiode, in welcher eine dünne Akkumulationstorfschicht abgesetzt wurde.

Die in den höchsten Gegenden des Gebiets gelegene Lagerfolge von Pikku-Miettilä (Abb. 5) repräsentiert die Vegetationsentwicklung im Vorfeld der Salpausselkäs und eine relativ alte Situation der Uferverschiebung der Ostsee im heutigen Niveau von ca. $117 \mathrm{~m}$ ü.d.M. PikkuMiettilä liegt etwa $2 \mathrm{~km}$ südwärts vom 1 . Salpausselkä (Abb. 2, Punkt 3). An dieser Stelle senkt das dem Salpausselkä vorgelagerte Gelände sich nicht deutlich südwärts, sondern besteht aus einer sanft gewellten Felstopographie, die von glazifluvialen und Moränenablagerungen ausgeglichen oder gesäumt ist.

Die anorganischen Grundsedimente von Pikku-Miettilä bestehen aus einer im Alleröd und in der jüngeren Dryaszeit entstandenen Feinsandablagerung. Die Gyttjabildung setzte in der jüngeren Dryaszeit ein. Die Schluff- und Gyttjasedimente aus dem jüngeren Dryas haben eine Kleinsee-Diatomeenflora (in der Gyttja sehr reich). Die fraglichen Sedimente können nicht im Baltischen Eissee abgesetzt worden sein, weil das Sedimentationsbecken deutlich höher liegt als die benachbarten Plateaus des 1. Salpausselkä. Der fragliche homogene Feinsand ist seinem Wesen nach auch kein spätglaziales Tiefwassersediment wie die gebänderten Sedimente. Wahrscheinlich ist Pikku-Miettilä zu der Zeit, wo der Feinsand abgelagert worden ist, eine Insel im Baltischen Eissee gewesen, die eine arme, steppenartige Vegetation besass. In diesen Verhältnissen konnte der Wind in den damaligen Niederungen oder Weihern, wo heute Moorbecken liegen, ungehindert Feinsand zusammenwehen.

Im Vorfeld des Salpausselkä ist die oberflächliche Ablagerung oft Feinsand. Um ein Bild davon zu gewinnen, in welchem Ostseestadium dieser Feinsand sedimentiert wurde, haben wir in einigen Niveaus aus ca. $10-20 \mathrm{~cm}$ Tiefe Proben für Diatomeenanalysen genommen. Die meisten Diatomeen enthielt die in Änkilä im 


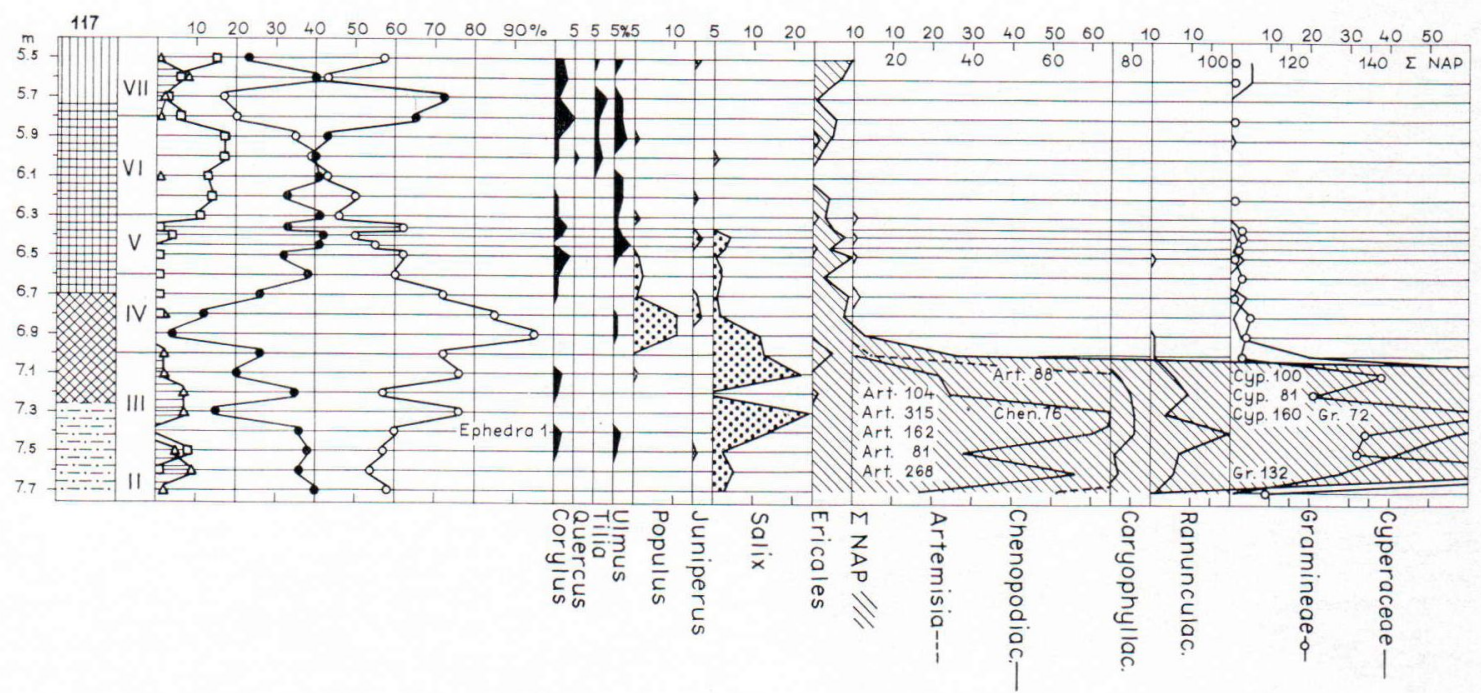

Abb. 5. Pollendiagramm des Moors von Pikku-Miettilä.

Niveau von etwa $57 \mathrm{~m}$ genommene Probe. Die dominante Art war darin Pinnularia borealis (71 $\%$ ) und an zweiter Stelle Hantzschia ampbioxys $(24 \%)$. Ausserdem enthielt die Flora die Arten Eunotia praerupta, Pinnularia viridis var. sudetica, Hantzschia amphioxys var. capitata sowie das Fragment einer Salzwasserform, Coscinodiscus asteromphalus. Mit Ausnahme der letztgenannten waren die anderen unversehrt und Kleinwasserformen, von denen u.a. die dominanten Arten auch auf dem Lande gedeihen (u.a. Harder 1948 und Lund 1945). Höchstwahrscheinlich sind auch die fraglichen wohlerhaltenen Formen nach der Verlandung dort gewachsen und vom Regenwasser tiefer in das Sediment hineingespült worden. Das Fragment der Salzwasserform dagegen repräsentiert eine aus der letzten Ablagerung stammende oder noch ältere (interglaziale) marine Sedimentationsphase. In den drei übrigen superfiziellen Feinsandablagerungen aus dem Vorfeld wurden nur ein paar Diatomeenarten süssen Wassers und feuchten Bodens angetroffen.

In Südost-Finnland setzt sich der 1. Salpausselkä auf der Distalseite mehr als im westlichen Teil in Verzweigungen und Osern fort. Andererseits ist dieses Gebiet höher und hügeliger als durchschnittlich. Dass im Vorfeld so viele glazifluviale Bildungen liegen, kommt möglicherweise daher, dass in dem abschmelzenden Inlandeis viele Spalten aufrissen, insbesondere an den grossen Bruchspaltenzonen des Felsgrundes. $\mathrm{Da}$ in dem seichten Wasser die Eisschollen nicht fortgetrieben wurden, war auch der abtauende Eisrand zerlappt und zerstückelt. Demgemäss wäre in der Zeit, wo der Bogen des Salpausselkä zustande kam, das Vorfeld mindestens noch in einer Zone von Eis bedeckt gewesen, wo heute zerstreute oder mehr einheitliche glazifluviale Ausläufer liegen. Der bedeutsamste radiale Ausläufer des Ersten Salpausselkä liegt in der südlichen Partie des von NW nach SE streichenden Bruchtals des Torsanjärvi, auf der Südostseite. Die Aufschüttung ist verhältnismässig einheitlich, ihre Oberfläche ist plateauartig (ca. 100$112 \mathrm{~m}$ ) und hat Toteisgruben. Weil die Bildung in einem Bruchtal liegt, wo die topographischen Unterschiede gross sind, hat sie dazu beigetragen, dass das Schmelzwasser sich dort ansammelte, was eine intensive Akkumulation am und vor dem Ersten Salpausselkä zur Folge hatte.

Die Verbreitung der glazifluvialen Gebilde und die Schrammenrichtungen in der weiteren 


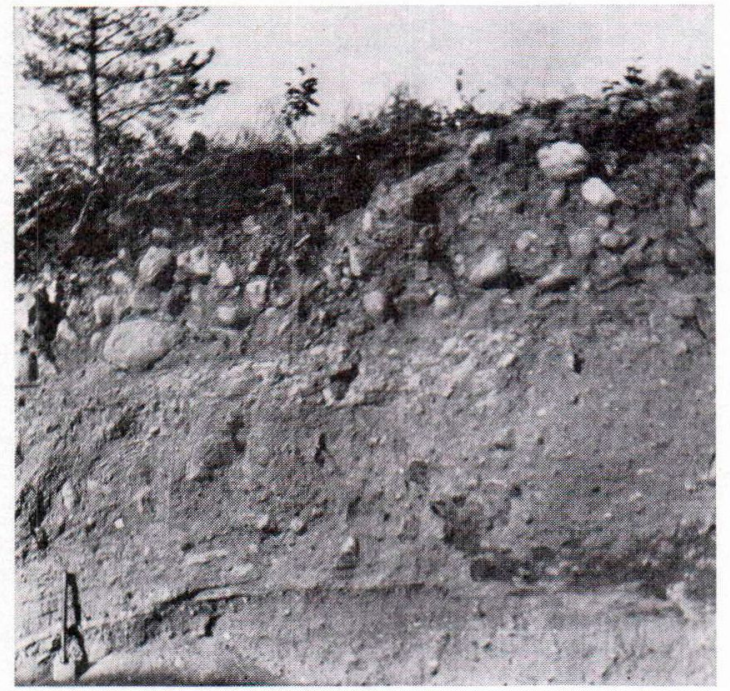

Abb. 6. Bodenaufschluss im Proximalteil des Ersten Salpausselkä in Koitsanlahti, Parikkala. In der Mitte sieht man die Moränenplatte, die oben vom Ufersediment und unten von einer glazifluvialen Ablagerung begrenzt ist.

Umgebung hat Berghell (1904) beschrieben. Demnach entsprechen die Längsrichtungen der glazifluvialen Gebilde im Vorfeld dem Verlauf der Schrammen. Diese beiden ihrerseits wurden dadurch beeinflusst, dass das grosse, über $200 \mathrm{~m}$ tiefe Becken des Ladogasees den Eisstrom auf sich zog, solange der Eisrand noch bis zum Ladogasee reichte. Die von der Bewegungsrichtung des Inlandeises abweichenden Richtungen der Oser gehen auf die von der Tektonik des Felsgrundes abhängigen, weitreichenden und grossen topographischen Variationen des Untergrundes zurück.

\section{Die Zone des Ersten Salpausselkä}

Der in dem Untersuchungsgebiet einbegriffene Teil des Salpausselkä ist eine auf relativ hohem und ebenem Untergrund gut entwickelte Randbildung des Inlandeises. Er ist aus zwei Partien aufgebaut, nämlich ein sanft südostwärts abfallendes, aus sortiertem Material bestehendes Plateau sowie der aus schlechter sortiertem Material zusammengesetzte, grubig-hügelige Proxi- malteil. In dem Aufschluss von Koitsanlahti im Proximalteil des Salpausselkä ist eine ca. $1.5 \mathrm{~m}$ dicke, stark sandige Moränendecke zu sehen (Abb. 6). Der Bodenaufschluss liegt in etwa $100 \mathrm{~m}$ Höhe. Die Moränendecke ist von einem ca. $1.3 \mathrm{~m}$ mächtigen Ufersediment überlagert, und unterhalb von ihr liegt glazifluvialer Kies und Sand, von dem ca. $2 \mathrm{~m}$ aufgeschlossen sind. Im Proximalteil liegen die Moränenablagerungen möglicherweise auch sonst öfters auf glazifluvialen Sedimenten.

Schwächer ausgebildet ist der Erste Salpausselkä in der Gegend von Rautjärvi in einem relativ hohen Gebiet. Hier besteht er aus verstreuten glazifluvialen Hügeln, die von kleinen Tälchen durchzogen sind.

Der bedeutsamste Bodenaufschluss des 1. Salpausselkä in dem Untersuchungsgebiet liegt in Änkilä westlich vom Kokkolanjoki (Abb. 2, Punkt 4), wo der Salpausselkä eine Breite von ca. $400 \mathrm{~m}$ hat. Der Aufschluss durchschneidet die Ablagerungen des Distalteils bis zu einer Tiefe von mehr als $15 \mathrm{~m}$. Das fragliche ebenflächige Plateau liegt etwa $100-103$ m ü.d.M. Das sanft wellige Gelände des Proximalteils, wo es auch Sölle gibt, steigt deutlich über diese Höhe hinauf. Die Ablagerungen der distalen Partie sind auf Abb. 7 und $8 \mathrm{zu}$ sehen. Die Schichtung ist deltaartig, und man sieht die horizontale Schichtung im oberflächlichen Teil sowie die distalwärts abfallenden, diagonale Schichtung der Mittelpartie. Der horizontal geschichtete Teil hat eine Mächtigkeit von 1$2 \mathrm{~m}$. Die obere Partie der schräggeschichteten Ablagerung ist waagrecht durchgeschnitten (Abb. 8). Das Sediment besteht vorwiegend aus Sand und Kies ohne deutlichen Wechsel. Das Gefüge der Ablagerung und die grossen Ausmasse der Akkumulation sind charakteristisch für eine im Wasser abgesetzte glazifluviale Bildung. Der Hauptteil der Aufschüttung dürfte im Schmelzstadium des Inlandeises als ein glazifluviales Delta entstanden sein. Die Deckschicht entspricht der Oberflächenablagerung eines normal entwickelten Deltas. Wenn die Deltafläche später 


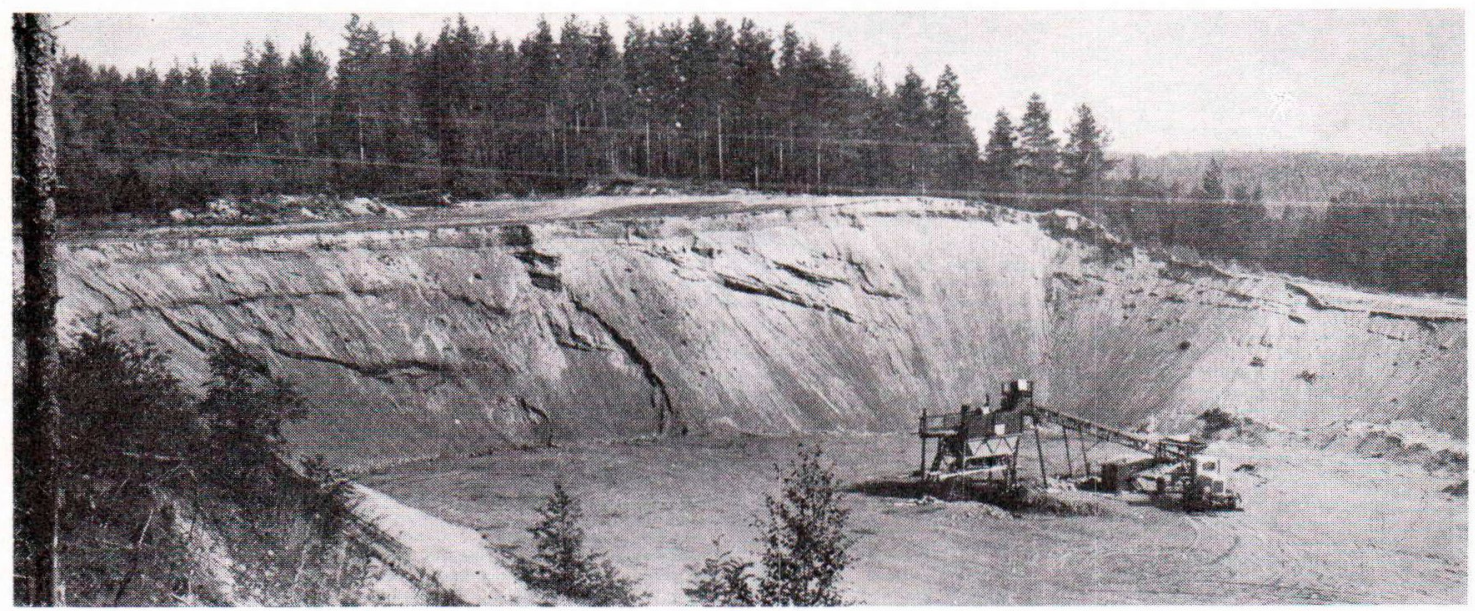

Abb. 7. Bodenaufschluss im Randdelta des 1. Salpausselkä in Änkilä.

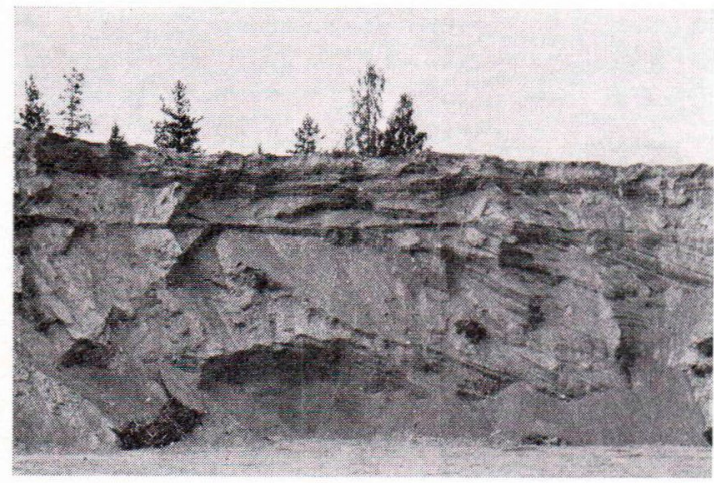

Abb. 8. Detail von der Schichtstruktur in dem Aufschluss von Abb. 7.

durch die Stranderosion bearbeitet worden wäre, müsste dies als eine Erosionsfläche zu sehen sein.

In dem grossen Bodenaufschluss von Änkilä im distalen Teil des Ersten Salpausselkä sind keine Spuren von einer eventuellen Oszillation des Eisrandes zu sehen. Die Moränenplatte im Proximalteil des benachbarten Koitsanlahti spiegelt vielleicht nur eine an den Proximalteil anschliessende Oszillation wider.

Kennzeichnend für den 1. Salpausselkä sind gut ausgebildete, ca. 100-105 m hoch liegende Plateaus, die manchmal durchweg höher sind als die Umgebung. Nicht selten schliesst an sie in der proximalen Partie ein Stück von einer welligen, höheren Salpausselkä-Randbildung an. Am bedeutendsten sind u.a. das weite Plateau nördlich vom See Immalanjärvi, wo es u.a. Sölle gibt, das Plateau von Torsanjärvi-Laikko, die Sandheide von Kivijärvi im Kirchspiel Simpele sowie die Sandheide von Poutala in Parikkala. Nach Sauramo sind diese Plateaus im Baltischen Eissee I aufgeschüttete Randdeltas.

Die Diatomeenanalyse vom Feinsand aus der Oberflächenpartie der Sandheide von Kivijärvi ergab eine Diatomeenflora kleinen Gewässers oder trockenen Bodens mit einem Pinnularia borealis-Maximum von mehr als $80 \%$. Hantzschia amphioxys war die zweitreichlichste Art. Offenbar ist auch diese Flora erst nach der Sedimentation aufgekommen und vermittelt kein Bild von der Situation z.Zt. der Ablagerung.

Vennonvaara ist in dem Untersuchungsgebiet die höchste Erhebung der Ersten Salpausselkäzone, ca. $150.5 \mathrm{~m}$ ü.d.M. Sie liegt in dem uneinheitlichen Proximalteil des Salpausselkä. Die Kuppe des Vennonvaara ist ausgespülte und teilweise eingeebnete Moräne. Abb. 9 zeigt die Korngrössen der ausgespülten Oberflächenschicht in ca. $0.3 \mathrm{~m}$ Tiefe. Die Auswaschung macht sie auch am Hang in ca. 135-145 m Höhe geltend, wo der Felsgrund blossliegt. Klare Uferbildungen sind in der näheren Umgebung keine angetroffen worden, wohl aber einige kleinere in dem welligen Gelände ca. $700 \mathrm{~m} \mathrm{NE}$ 


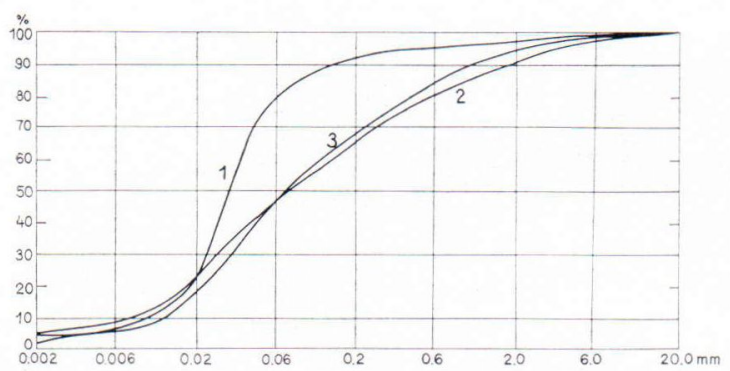

Abb. 9. Korngrössenkurven von den Oberflächensedimenten einiger über die Umgebung emporragender Scheitelflächen. 1. Riuttavaara, $172.4 \mathrm{~m}$ ü.d.M.; 2. Vennonvaara, $150.5 \mathrm{~m}$; 3. Korpivaara, Rautjärvi, $135 \mathrm{~m}$.

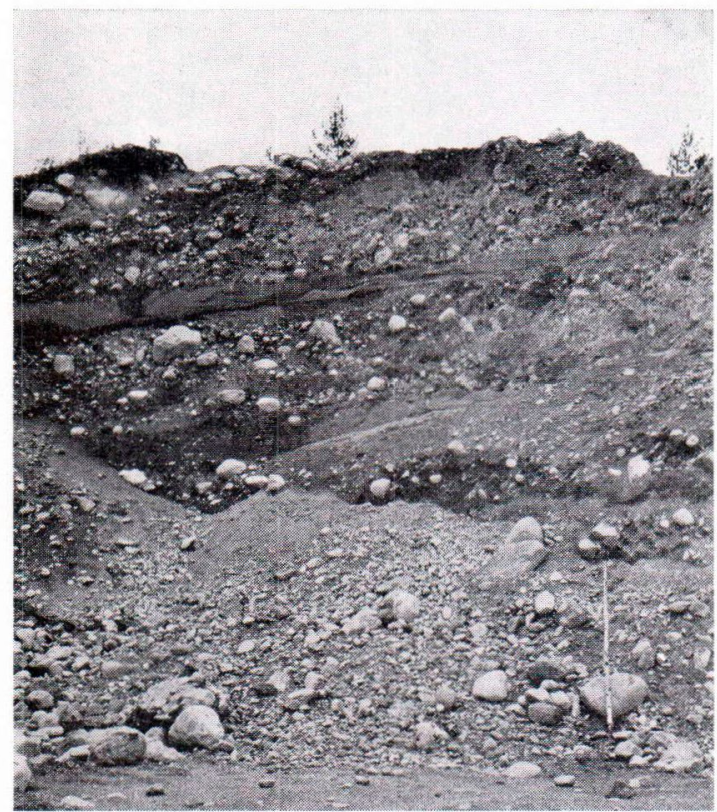

Abb. 10. Bodenaufschluss im Randteil eines Oszugs in Virmutjoki. Steiniges, schwach sortiertes Material und dazwischen Sand. Höhe des Aufschlusses etwa $7 \mathrm{~m}$.

vom Vennonvaara. Dort kommt eine abgespülte Zone vor, ähnlich dem höchsten Ufer, und darunter ein Uferhang in ca $130 \mathrm{~m}$ ü. d. M. Der Buckel oberhalb von der abgespülten Zone ist hier eine Moränenkalotte, und unterhalb im Ostteil liegt ein kleiner, nackter Felsen. In etwa $125 \mathrm{~m}$ Höhe liegt ausserdem ein kleiner Uferhang. Auch noch unterhalb von dem letzteren, ca. $107 \mathrm{~m}$ ü.d.M., findet sich ein Uferhang (Baro- metermessungen). Ganz offenbar war die ganze oben beschriebene Höhenzone vor der Entstehung des Plateaus des 1. Salpausselkä vom Wasser überflutet. Wenn die vorn beschriebene hohe Wasserphase erst nach der Entstehung des 1. Salpausselkä-Plateaus eingetreten wäre, wären in diesem Zusammenhang auf dem Plateau mit aller Wahrscheinlichkeit anfänglich Sedimente tieferen Wassers zusammen mit von den Eisschollen verfrachteten Steinblöcken abgesetzt worden. Später hätte der abgesunkene Wasserspiegel vermutlich das proximale grubig- hügelige Gelände ausgeglichen.

Auch von der Oberflächenpartie der Kuppe des Vennonvaara sowie vom Hang in ca. $125 \mathrm{~m}$ Höhe wurden Diatomeenanalysen gemacht. Die Resultate waren ähnlich wie die von der Sandheide von Kivijärvi, wennschon mit viel geringeren Individuenmengen.

Die Auswaschung der höchsten Stellen ist älter als der Erste Salpausselkä, und sie ist kein Beweis für ein Grossgewässer während des hohen Wasserstands, weil grosse Uferbildungen fehlen. Es ist nicht ausgeschlossen, dass die Abspülung in Eisspalten an solchen Stellen stattgefunden hat, wo anstatt von Akkumulation die Erosion am Werk gewesen ist.

\section{Das Zwischengelände der Salpausselkäs}

In dieser ca. $20 \mathrm{~km}$ breiten Zone liegen zahlreiche Seen, von denen viele in der Subborealzeit zum Gross-Saimaa gehörten (Hellaakoski). Im Präboreal erstreckte sich das Yoldiameer noch ausgedehnter in tiefergelegene Gegenden. Der Baltische Eissee seinerseits überflutete einen weiten Teil des Gebiets, wobei die relativ hohen Felsen und Berge einen Schärenhof bildeten.

In dem Zwischengelände laufen mehrere, im allgemeinen abgeflachte glazifluviale Randbildungen oder Längsoser. Einer von den deutlichsten Oszügen zwischen den Salpausselkäs läuft an einem Bruchtal von der Nordseite des Plateaus vom Immalanjärvi nach Eräjärvi. In 


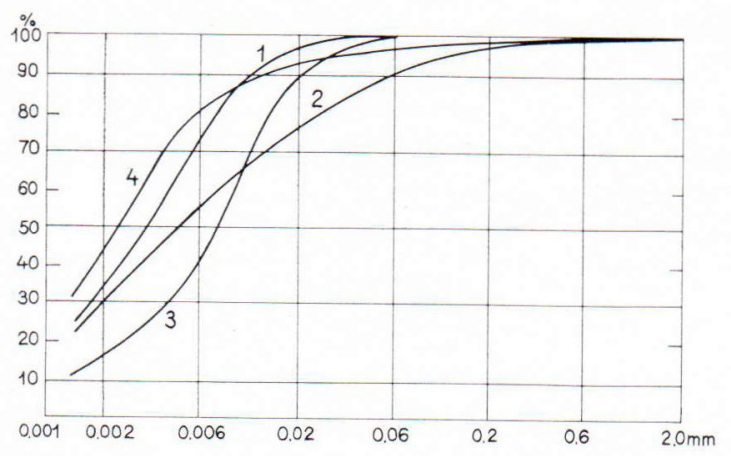

Abb. 11. Korngrössenkurven von Bändertonen des Gebiets. 1. Suomaa in Änkilä, 2. Virmutjoki, 3. Joukio, 4. Kiteenlahti.

Ruokolahti in der Gegend von Virmutjoki gibt es einige Bodenaufschlüsse, wo die Struktur des Oses zu sehen ist. Der grosse, bis zu etwa $15 \mathrm{~m}$ Tiefe hinunterreichende Aufschluss im Nordteil des Oses (Abb. 2, Punkt 5) lässt glazifluviale Sand- und Kiesablagerungen erkennen. Etwa 2 $\mathrm{km}$ südwärts von hier, in der westlichen Partie des Oses liegt ein Aufschluss in schwächer sortiertem Material. In der Westwand sieht man drei übereinander liegende Decken fast moränenartigen Materials, die durch glazifluviale Sandschichten voneinander getrennt sind (Abb. 10). Die Steine sind schwach zugerundet, und das Material überhaupt ist schlecht sortiert, was mo- ränenartige Beschaffenheit anzeigt. Die schwache Sortierung kommt wahrscheinlich daher, dass der Sedimentationsort in dem glazifluvialen Stromsystem abseits gelegen war. Wie aus dem Verlauf des fraglichen Oses am Rand der Bruchtäler hervorgeht, ist er in einer Eisspalte aufgeschüttet worden, und zwar nahe am Rand der Spalte, wo sich die zeitweilig intensive Aktivität des abschmelzenden Eises geltend machen konnte. So wurden die moränenartigen Decken aufgeschüttet, während wiederum die zwischengelagerten glazifluvialen Sandschichten von der eigentlichen glazifluvialen Strömung in Zeiten, wo die Eisspalte sich verbreiterte, sedimentiert wurden. Spuren von Oszillation des Eisrandes vertikal zu den Längsspalten und Osern sind in diesem Gebiet im Rahmen der spärlichen Schrammenbeobachtungen keine gefunden worden, aber die Erscheinung lässt sich u.a. vielerorts in Nordkarelien nachweisen (Repo 1954, 1957).

In dem oben besprochenen Aufschluss im Osgebiet von Ruokolahti ist in der Ostwand ausserdem oben eine Bändertonserie zu sehen. Der Warvendicke nach zerfällt sie horizontal in drei Teile. Im untersten, im ganzen $30 \mathrm{~cm}$ hohen Abschnitt sind die Warven $0.5-1.5 \mathrm{~cm}$ dick, in dem nächsten Abschnitt von $20 \mathrm{~cm}$ beträgt die Warvendicke ca. $3 \mathrm{~cm}$ und im obersten, $70 \mathrm{~cm}$

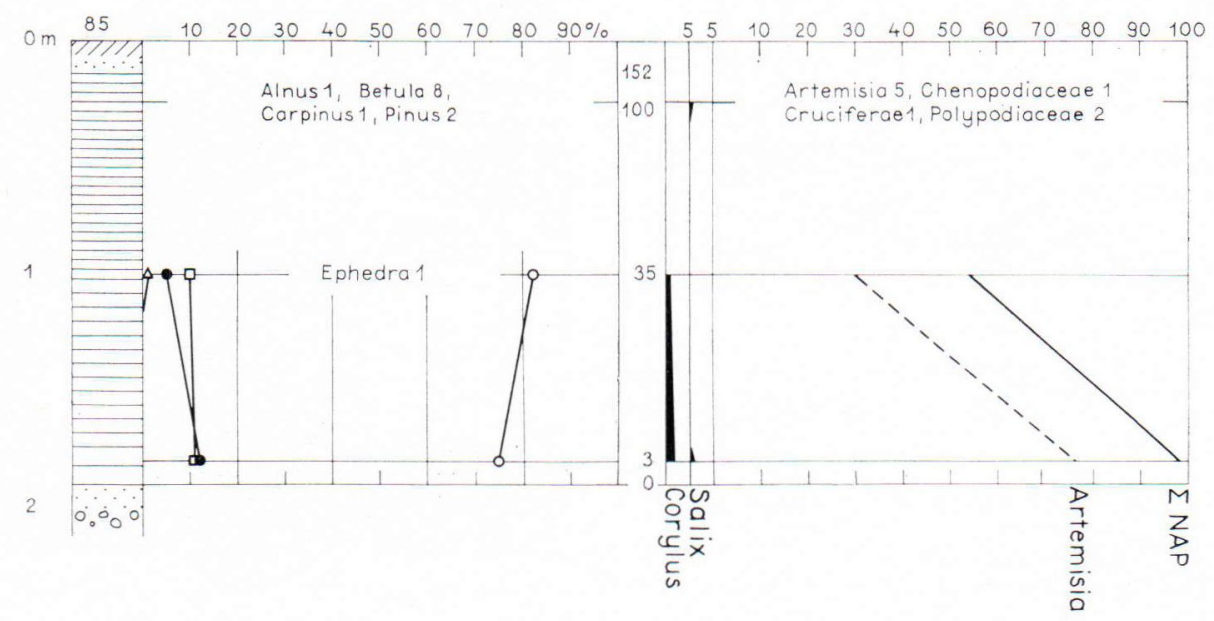

Abb. 12. Pollendiagramm vom Bändertonsediment beim Haltpunkt Joukio. Anzahl der Warven: $0-152$. 


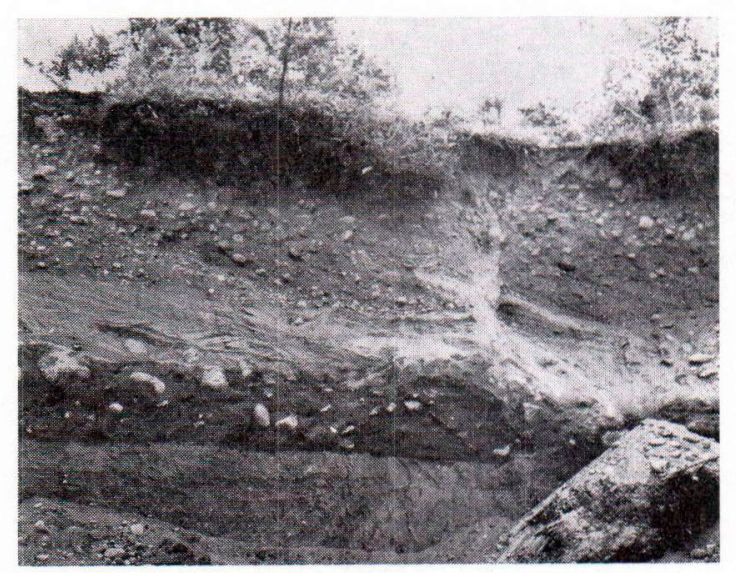

Abb. 13. Aufschluss in der glazifluvialen Randbildung in Varmonniemi. In der Mitte sieht man die horizontale Moränenplatte.

hohen Abschnitt durchschnittlich $0.7 \mathrm{~cm}$. In der Korngrösse dieser Sedimentabschnitte besteht kein wesentlicher Unterschied. In der mittleren Partie ist die Bänderung nur schwach zu sehen, und der ganze Abschnitt bildet eine helle Zwischenschicht. Die Schichtenfolge erinnert etwas an Sauramos (1923) Beschreibung vom mittleren und oberen Teil der Schichtenfolge von Jokela. Dort ist die helle, tonarme Zwischenschicht nach Sauramo beim Rückzug des Eisrandes zum 2. Salpausselkä entstanden, während der dunklere, breiter gebänderte Oberteil im Lauf des 2. Salpausselkästadiums abgelagert worden wäre. In Ruokolahti ist der Bänderton bedeutend magerer als das entsprechende Sediment in Westfinnland und offenbar in seichtem Wasser abgesetzt. Die dicken Warven der Mittelpartie zeigen Oszillation des Eisrandes oder starkes Abtauen des Eises an, was am ehesten mit der Bildung des 2 . Salpausselkä in Verbindung zu setzen wäre. Der Abstand vom 2. Salpausselkä ist ca. $10 \mathrm{~km}$.

Die Korngrössenanalysen, die von einigen Tonsedimenten aus verschiedenen Gegenden des Untersuchungsgebiets gemacht worden sind, lassen erkennen, dass die Tone so ziemlich gleiche Korngrössen haben; es sind relativ magere Schlufftone (Abb. 11).

Am Bahndurchschnitt beim Haltpunkt Joukio in Parikkala trat eine ca. $2 \mathrm{~m}$ mächtige gebänderte Tondecke zutage (Abb. 2, Punkt 6). Auf dem Grund der Schichtenfolge liegen Sand und Steine. Im unteren und mittleren Abschnitt der Tonschicht beträgt die Warvendicke ca. $3 \mathrm{~cm}$. Von $0.9 \mathrm{~m}$ Tiefe bis hinauf zur Oberfläche sind die Warven erheblich dünner, und die ganze Schichtenfolge entspricht ca. 150 Jahren. Die relativ dicken Warven der unteren und mittleren Partie sprechen dafür, dass der Eisrand nicht sehr weit entfernt war (vgl. Ignatius 1958). Nach dem in grösseren Abständen gemachten Pollendiagramm (Abb. 12) scheint der Ton in der ausgehenden Jüngeren Dryaszeit in einem relativ niedrigen Tal (85 m.ü.d.M.) abgesetzt worden zu sein.

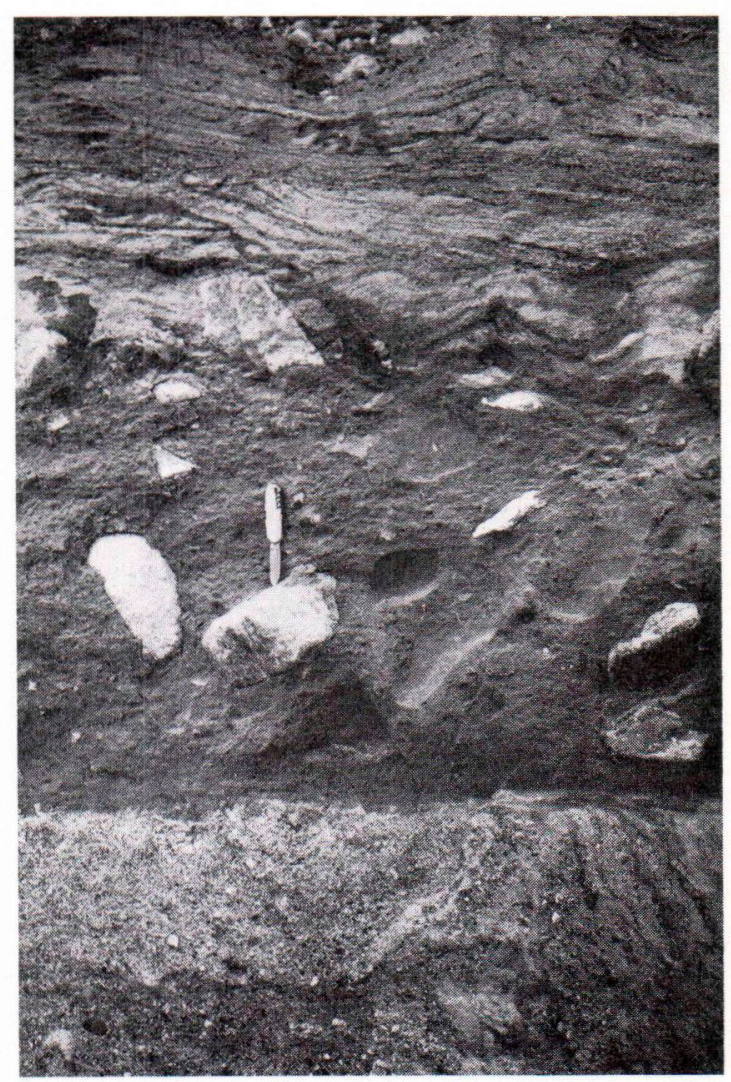

Abb. 14. Detaillierteres Bild von den Sedimenten der Bildung von Varmonniemi. Oben die steinige Uferablagerung, darunter glazifluvialer Sand, die Moränenplatte sowie glazifluvialer Kies und Sand. 


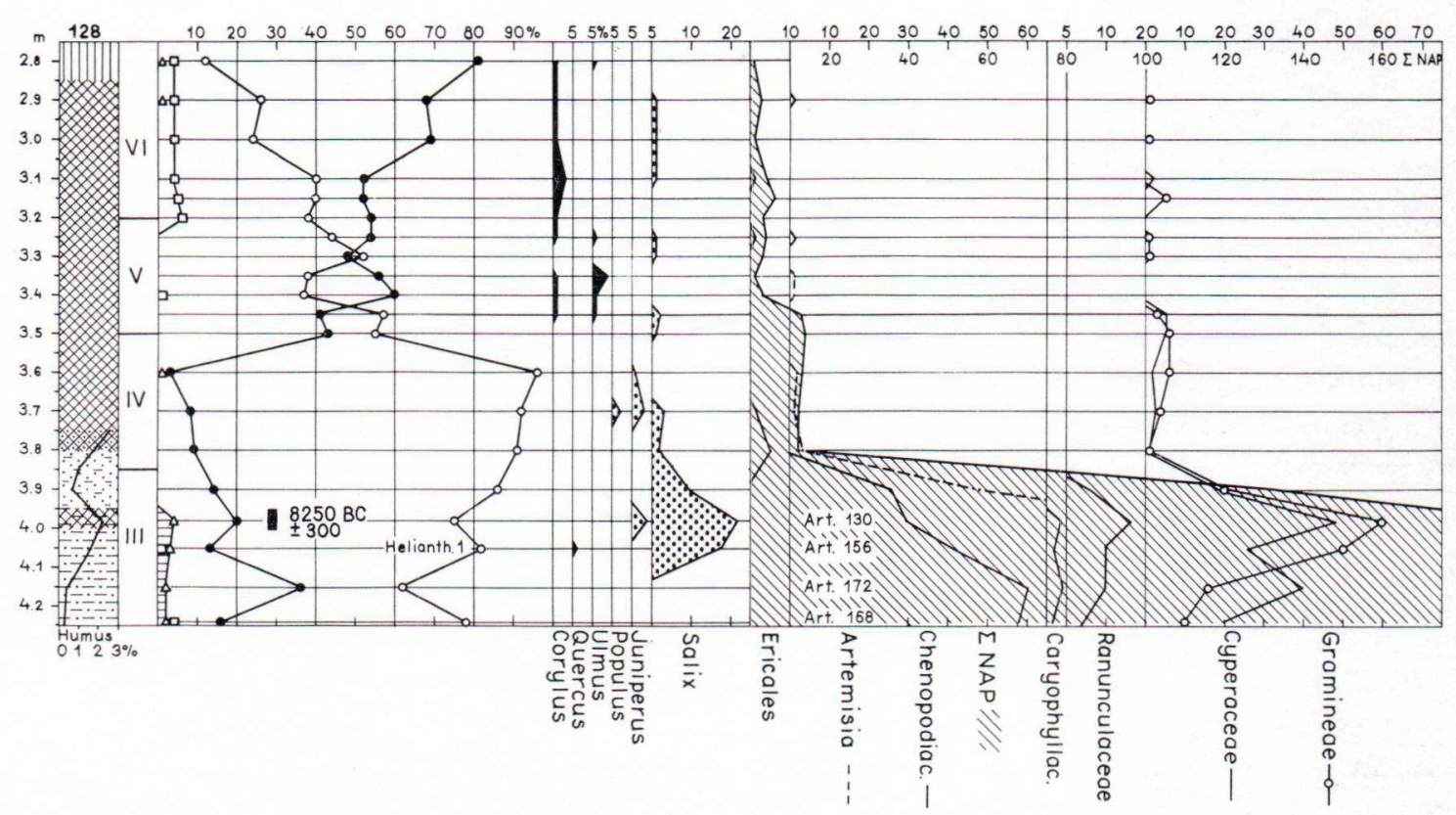

Abb. 15. Pollendiagramm von Koivusilta.

Das Bändertonsediment hat - abgesehen von der obersten Partie - eine sehr arme Diatomeenflora. Der oberste Teil hat eine relativ artenreiche Kleinwasserflora, die vorherrschenden Arten sind Pinnularia mesolepta (20 St.), Hantzschia amphioxys (11), Surirella ovata var. pinnata (6), Gomphonema parvulum (5) und Meridion circulare (3). Ausser Kleinwasserformen sind viele von den genannten Formen auch aerophil.

Der Oszug, der in der Gegend von Parikkala über Kaukola - Rautalahti läuft, hält ausnahmsweise Nord-Süd-Richtung ein, welche Richtung auch manche aus den Salpausselkäs vorspringende Ausläufer haben. Auch in diesem Falle, wie überhaupt in Ostfinnland, ist der Os in einer von einem Bruchtal im Felsgrund ausgerichteten Spalte entstanden. In der Zone zwischen den Salpausselkäs muss aus der uneinheitlichen Lage der Ossysteme zu schliessen der zurückweichende Eisrand von vielen Spalten zerrissen gewesen sein.

In der Spaltenzone hat aus klimatischen Gründen Bewegung zwischen den Spaltenrändern sowie glazifluviale und glazigene Akkumulation stattgefunden. Diese Tätigkeit hat in den glazifluvialen Systemen im Laufe relativ langer Zeit unterschiedliche Schichtenfolgen abgelagert und die Orientierung der Gebilde beeinflusst. Die glazifluvialen Aufschüttungen haben in Ostfinnland und im Gebiet jenseits der Grenze oft grössere Dimensionen als im Westen. In dem Untersuchungsgebiet und in den Salpausselkäund Ospartien von Ostfinnland überhaupt sieht man auch keine von den Eisschollen verfrachteten Blockfelder wie weiter im Westfinnland.

Spuren von Oszillation des Eisrandes sieht man in Varmonniemi, Kesälahti, in einer kleineren glazifluvialen Randbildung (Abb. 2, Punkt 7). In dem Aufschluss ist unter der aus Kies und Geröll bestehenden Uferablagerung und glazifluvialem Sand eine ca. $1 \mathrm{~m}$ mächtige Moränendecke zu sehen, die verhältnismässig grosse Blöcke enthält (Abb. 13 und 14). Unterhalb davon ist das glazifluviale Material Sand und Kies. Die Moränendecke ist unten eben und gleichmässig abgegrenzt und hat die glazifluviale 
Ablagerung scharf geschnitten. Die Moränendecke dürfte von keiner ganz geringfügigen lokalen Oszillation des Eisrandes geschaffen worden sein. Nach der Entstehung der Moränendecke ist die glazifluviale Tätigkeit an dem Ort zunächst relativ schwach gewesen und hat das ca. $1 \mathrm{~m}$ dicke, kein grobes Material enthaltende, geschichtete Sediment abgesetzt. Die gröbere Uferablagerung kann aber aus ursprünglich glazifluvialem Oberflächenmaterial entstanden sein.

Sonstige Spuren davon, dass Moräne auf glazifluviales Material aufgeschoben worden ist, sieht man u.a. in Parikkala in dem Osaufschluss beim Dorf Joensuu. Die dem glazifluvialen Material aufgelagerte Moränendecke hat eine Mächtigkeit von ca. $1.5 \mathrm{~m}$.

Da es in dem Gebiet, obwohl es ziemlich wenig Aufschlüsse in Osmaterial gibt, trotzdem mehrere Spuren von Unterbrechung des Abschmelzprozesses bis zu Aktivierung des Inlandeises zu sehen sind, kann die Erscheinung in der Zwischenzone der Salpausselkäs in dem fraglichen Gebiet für relativ charakteristisch gelten.

Die höchsten Punkte im Zwischengelände der Salpausselkäs sind Haukkavaara $(171.9 \mathrm{~m})$ und Riuttavaara $(172.4 \mathrm{~m})$. Beide liegen in der Mitte zwischen den Salpausselkäs im Moränengebiet. Die Kuppe des Haukkavaara ist Fels, aber der oval geformte, abgerundete Buckel des Riuttavaara hat an der Oberfläche ziemlich gut sortier-
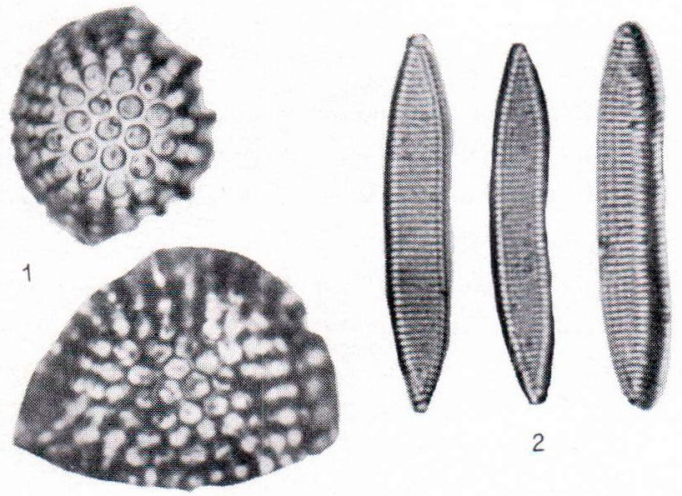

Abb. 16. Diatomeen der spätglazialen Sedimente: 1. Stephanopyxis turris var. polaris. 2. Hantzschia pseudomarina var. obtusa. Etwa 500-fache Vergrösserung ten Feinsand, wie aus der Korngrössenanalyse ersichtlich ist (Abb. 9). Das feinkörnige Oberflächensediment ist offenbar nicht als Uferablagerung an einem grossen, offenen Gewässer abgesetzt worden, denn die groben, sortierten Sedimente fehlen. Auch die in den Sedimenten angetroffene Diatomeen flora umfasst nur 15 in Kleingewässern und teils auch auf dem trockenen Land wachsende Exemplare, und zwar folgende Arten: Melosira granulata var. angustissima (5), Pinnularia borealis (4), Hantzschia amphioxys (2), Eunotia praerupta und Pinnularia viridis var. sudetica. Der Feinsand ist offenbar auf der Moräne im Abschmelzstadium des Inlandeises unter relativ ruhigen Verhältnissen in der von Spalten durchsetzten Randzone des Inlandeises abgelagert worden.

\section{Die Entwicklung im Licht der Pollen-und Diatomeen- untersuchungen}

Die höchste untersuchte Schichtenfolge ist in einem kleinen Reisermoor im Dorf Sutela in Rautjärvi in ca. $136 \mathrm{~m}$ Höhe erbohrt worden (Abb. 2, Punkt 8). Die Umgebung ist Moräne und abgespülter Fels. Die Bodensedimente des Moors in ca. 2.7-2.45 cm Tiefe bestehen zuunterst aus Schluff und Feinsand. Der Pollendatierung gemäss sind sie in der Jüngeren Dryaszeit entstanden. Der gewöhnlichste Pollen in dem Schluffsediment ist Artemisia (252-295/100 BP). Zusammen mit Gramineae und Chenopodiaceae spiegelt er tundra-steppenartige Vegetation wider.

Der Schluff und Feinsand enthält eine reiche Diatomeenflora süsser Kleingewässer. Die Sedimentation hat also in einem oberhalb vom Baltikum gelegenen Becken stattgefunden. Infolge der später, seit Beginn der Präboreals vor sich gehenden Eutrophierung wurde zunächst Gyttja gebildet, dann Akkumulationstorf sowie in der Borealzeit Seggentorf und im beginnenden Atlantikum Sphagnumtorf.

Das Pollendiagramm der Schichtenfolge von Koivusilta (Abb. 15) zeigt eine Sedimentations- 
und Vegetationssukzession von der Jüngeren Dryaszeit bis zum Früh-Atlantikum. Koivusilta ist ein Mooracker im Kirchspiel Saari und liegt in etwa $128 \mathrm{~m}$ Höhe (Abb. 2, Punkt 9). Die Lagerfolge zerfällt in die klar unterscheidbaren Zonen III, IV, V und VI. Das beträchtliche NBP-Maximum der Jüngeren Dryaszeit umfasst hunderte von NB-Pollen auf hundert Baumpollen. Es ähnelt dem Pollenspektrum des Schluffs unterhalb der nach dem $\mathrm{C}^{14}$-Verfahren datierten Stelle in der früher von uns beschriebenen Schichtenfolge von Mustalampi (Repo und Tynni 1967).

In der Lagerfolge von Koivusilta liegt in 4.0 $\mathrm{m}$ Tiefe im Schluff eine $5 \mathrm{~cm}$ dicke Zwischenschicht gyttjahaltigen Schluffs, was auch aus den nach dem areometrischen Verfahren durchgeführten Humusbestimmungen hervorgeht (Abb. 15). Der Pollenanalyse gemäss ist die fragliche Zwischenschicht in der Jüngeren Dryaszeit entstanden. Isotopes Inc., New Jersey, hat von dem gyttjahaltigen Sediment eine $\mathrm{C}^{14}$-Datierung gemacht, und das Resultat war $8250 \pm 300$ v.Chr. Die Datierung entspricht u.a. nach der in Schweden und Deutschland üblichen Einteilung der ausklingenden Jüngeren Dryaszeit (oder im Rahmen der negativen Fehlergrenze dem Beginn des Präboreals). In Koivusilta hat die älteste, organische Stoffe führende Schicht somit ungefähr das gleiche Alter wie die älteste Gyttja-Ablagerung des auf der Distalseite des 1. Salpausselkä gelegenen Mustalampi in Ilomantsi.

Die in den tiefsten Sedimenten von Koivusilta in ca. $4.2 \mathrm{~m}$ Tiefe angetroffene Diatomeenflora besteht grössenteils aus Süss- und Brackwasserformen. An der fraglichen Stelle macht die SüBrForm Nitzschia angustata $56 \%$ aus, aber die zweithäufigste Kieselalge $(22 \%$ ) erinnert an Hantzschia pseudomarina Hust. Nach Hustedt ist die letztgenannte eine marine Form. Die betreffende Hantzschia-Art haben wir Hanzschia pseudomarina var. obtusa (A.Cl.) nov. comp. benannt (Abb. 16). Die Art ist nicht aus Finnland beschrieben, und über ihre ökologischen Ansprüche in Finnland ist ebenfalls nichts be- kannt. Möglicherweise auch diese Art ist SüssBrackwasserform. Die andere sichere Salzwasserform, Coscinodiscus asteromphalus, war nur durch ein Fragment vertreten. $10 \mathrm{~cm}$ weiter oben wurde nur eine Salzwasserdiatomee gefunden, nämlich Navicula peregrina.

Weiter oben im Schluff, in $4.05 \mathrm{~m}$ Tiefe, fehlten die Salzwasserformen. Neben den Arten kleinen Süsswassers dagegen befanden sich ein paar Planktonformen: Cyclotella bodanica (4\%) und Melosira islandica ssp. belvetica (1 \%). In dem gyttjahaltigen Feinsand wurde ausser der Diatomeenflora süsser Kleingewässer noch eine Navicula peregrina gefunden. Das Maximum bildete Fragilaria construen + var. venter $(52 \%)$. Auch der den gyttjahaltigen Feinsand überlagernde Feinsand enthielt nur eine Kleingewässer-Diatomeenflora.

Zusammenfassend lässt sich sagen, dass in der Gegend von Koivusilta eingangs der Jüngeren Dryaszeit die Sedimentation wahrscheinlich im spätglazialen Yoldiameer stattgefunden hat. Später in der Jüngeren Dryaszeit, vor der Ablagerung des gyttjahaltigen Feinsandes, wurde das heutzutage ca. $128 \mathrm{~m}$ ü.d.M. gelegene Niveau von diesem Meer abgeschnürt. Dieses Entwicklungsbild wird auch durch die Schichtenfolge von dem benachbarten Weiher Sippurilampi bestätigt.

Der Sippurilampi liegt im Kirchspiel Parikkala etwa $1 \mathrm{~km}$ südwärts von Koivusilta. Das Pollendiagramm von der an dem braunmoorartigen Ufer des Sippurilampi in ca. $118 \mathrm{~m}$ ü.d.M. erbohrten Schichtenfolge (Abb. 17) reicht bis zu den älteren anorganischen Sedimenten. Im Feinsand der unteren Partie ist das Maximum der NB-Pollen bedeutend niedriger als weiter oben im Ton, weshalb es nicht ausgeschlossen ist, dass sie schon im Alleröd abgesetzt worden ist. Der Schluff vom Sippurilampi hat, wie auch in Koivusilta, eine ca. $10 \mathrm{~cm}$ starke gyttjahaltige Zwischenschicht. Der Pollendatierung gemäss ist diese Schicht an beiden Stellen in der gleichen Zeit entstanden. Die Diatomeenflora der gyttjahaltigen Zwischenschicht ist relativ arm auch im Vergleich zu den Bodensedimenten (Tabelle 1). 
Tabelle 1.

Diatomeen der Schichtenfolge vom Weiher Sippurilampi $*=$ marine Formen

\begin{tabular}{|c|c|c|c|c|c|c|c|}
\hline Zone & \multicolumn{2}{|c|}{ IV } & \multicolumn{4}{|c|}{ III } & \multirow{2}{*}{$\frac{\text { II }}{685}$} \\
\hline Tiefe cm & 635 & 645 & 655 & 662 & 668 & 675 & \\
\hline Acbnantbes flexella ............. & - & 2 & - & - & - & - & - \\
\hline A. linearis var. pusilla ......... & 3 & - & - & - & - & - & - \\
\hline A. minutissima $\ldots \ldots \ldots \ldots \ldots$ & 1 & - & - & - & - & - & - \\
\hline - var. cryptocepbala ......... & 1 & - & - & - & - & - & - \\
\hline Amphora ovalis $\ldots \ldots \ldots \ldots \ldots$ & 1 & 2 & 1 & - & - & - & - \\
\hline 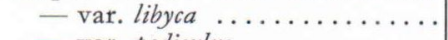 & - & 2 & - & - & - & - & - \\
\hline — var. pediculus ............. & - & - & - & - & 1 & - & - \\
\hline Anomoeoneis serians ............. & 一 & - & - & - & - & 1 & - \\
\hline 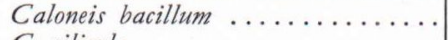 & - & 2 & 9 & - & - & - & - \\
\hline$C$. silicula $\ldots \ldots \ldots \ldots \ldots \ldots$ & - & 1 & 2 & - & - & - & - \\
\hline - var. truncatula ........... & 一 & 1 & - & - & - & - & - \\
\hline Cocconeis placentula ............. & - & - & 1 & - & - & - & - \\
\hline Cyclotella comta $\ldots \ldots \ldots \ldots \ldots$ & 2 & - & - & - & - & - & - \\
\hline C. kützingiana $\ldots \ldots \ldots \ldots \ldots$ & 1 & 一 & - & - & - & - & - \\
\hline Cymbella affinis...$\ldots \ldots \ldots \ldots$ & - & 1 & - & - & - & - & - \\
\hline C. aspera $\ldots \ldots \ldots \ldots \ldots \ldots \ldots$ & - & 1 & 2 & 一 & 80 & 63 & - \\
\hline C. cymbiformis $\ldots \ldots \ldots \ldots \ldots$ & - & 2 & - & - & - & - & - \\
\hline C. gracilis $\ldots \ldots \ldots \ldots \ldots \ldots \ldots$ & - & - & - & 一 & - & - & 2 \\
\hline C. belvetica $\ldots \ldots \ldots \ldots \ldots \ldots \ldots$ & - & - & 1 & - & - & 1 & - \\
\hline C. naviculiformis ............ & 1 & 1 & 1 & - & - & - & - \\
\hline C. prostrata ................ & - & - & - & 1 & - & - & - \\
\hline C. sp. fragm. . . . . . . . . . & - & - & - & 2 & - & - & - \\
\hline C. tumida ................ & - & - & 1 & - & - & - & - \\
\hline C. turgida $\ldots \ldots \ldots \ldots \ldots \ldots \ldots$ & 1 & 1 & - & - & - & 1 & 3 \\
\hline C. ventricosa $\ldots \ldots \ldots \ldots \ldots \ldots$ & 1 & - & - & - & - & 一 & - \\
\hline 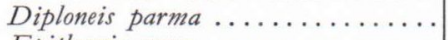 & - & 1 & - & - & - & 一 & - \\
\hline Epithemia arcus $\ldots \ldots \ldots \ldots \ldots$ & - & - & - & - & - & - & 1 \\
\hline E. proboscidea .............. & - & 2 & - & - & - & - & - \\
\hline E. zebra $\ldots \ldots \ldots \ldots \ldots \ldots \ldots$ & - & - & - & 2 & - & - & 1 \\
\hline - var. porcellus . ............ & 1 & 1 & - & - & - & - & 1 \\
\hline Eunotia bidentula ............. & 1 & 1 & 1 & - & - & - & - \\
\hline E. flexuosa $\ldots \ldots \ldots \ldots \ldots \ldots$ & - & - & - & - & - & - & 1 \\
\hline E. praerupta $\ldots \ldots \ldots \ldots \ldots \ldots$ & - & - & 2 & - & - & 1 & 1 \\
\hline E. veneris $\ldots \ldots \ldots \ldots \ldots \ldots \ldots$ & 1 & - & - & 1 & - & - & 1 \\
\hline Fragilaria bicapitata ........... & 2 & 一 & 一 & - & - & - & 一 \\
\hline F. brevistriata $\ldots \ldots \ldots \ldots \ldots \ldots$ & 3 & - & - & - & - & - & - \\
\hline$F$. construens $\ldots \ldots \ldots \ldots \ldots \ldots$ & 23 & 1 & - & - & 一 & - & 4 \\
\hline - var. venter $\ldots \ldots \ldots \ldots \ldots$ & 9 & 1 & - & - & - & - & 1 \\
\hline F. crotonensis $\ldots \ldots \ldots \ldots \ldots \ldots$ & 1 & - & - & - & - & - & - \\
\hline F. lapponica $\ldots \ldots \ldots \ldots \ldots \ldots$ & 5 & - & - & 一 & - & - & - \\
\hline$F$. pinnata $\ldots \ldots \ldots \ldots \ldots \ldots \ldots$ & 11 & 4 & - & - & 2 & - & - \\
\hline Frustulia rbomboides ............ & 一 & - & - & 一 & - & 1 & 1 \\
\hline Gompbonema acuminatum ......... & 一 & - & 1 & - & - & - & 1 \\
\hline - var. coronata $\ldots \ldots \ldots \ldots \ldots$ & 4 & - & - & - & - & 1 & 3 \\
\hline$G$. angustatum $\ldots \ldots \ldots \ldots \ldots$ & 1 & - & - & - & - & - & - \\
\hline G. gracile $\ldots \ldots \ldots \ldots \ldots \ldots$ & 1 & 1 & - & - & - & - & 1 \\
\hline Gyrosigma acuminatum $\ldots \ldots \ldots \ldots$ & - & 2 & - & - & - & - & 一 \\
\hline Hantschia ampbioxys ............ & - & 1 & 4 & 1 & 2 & 3 & - \\
\hline 一var. maior $\ldots \ldots \ldots \ldots \ldots \ldots$ & - & - & - & - & 2 & - & - \\
\hline H. elongata $\ldots \ldots \ldots \ldots \ldots \ldots$ & 一 & - & - & - & - & 3 & - \\
\hline * Mastogloia dansei var. streptoraphe .. & - & - & - & 1 & - & - & - \\
\hline 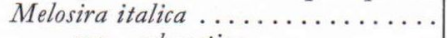 & - & - & - & - & - & - & 1 \\
\hline - ssp. subarctica $\ldots \ldots \ldots \ldots \ldots$ & - & - & - & - & - & - & 6 \\
\hline 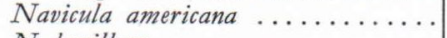 & 一 & - & - & - & - & - & 3 \\
\hline N. bacillum $\ldots \ldots \ldots \ldots \ldots \ldots$ & - & 1 & - & - & - & - & - \\
\hline N. cuspidata $\ldots \ldots \ldots \ldots \ldots \ldots$ & - & 1 & 1 & - & - & - & - \\
\hline$N$. dicepbala $\ldots \ldots \ldots \ldots \ldots \ldots$ & - & 5 & - & - & 1 & - & - \\
\hline$N \cdot$ pseudoscutiformis $\ldots \ldots \ldots \ldots$ & 2 & - & - & - & - & - & - \\
\hline
\end{tabular}


TABelle 1. (Fortsetzung)

\begin{tabular}{|c|c|c|c|c|c|c|c|}
\hline Zone & \multicolumn{2}{|c|}{ IV } & \multicolumn{4}{|c|}{ III } & \multirow{2}{*}{$\frac{\text { II }}{685}$} \\
\hline Tiefe $\mathrm{cm}$ & 635 & 645 & 655 & 662 & 668 & 675 & \\
\hline$N \cdot$ pupula $\ldots \ldots \ldots \ldots \ldots \ldots \ldots$ & 1 & 2 & - & - & - & - & 1 \\
\hline - var. rectangularis $\ldots \ldots \ldots \ldots$ & - & - & - & - & - & - & 5 \\
\hline$N$. radiosa $\ldots \ldots \ldots \ldots \ldots \ldots \ldots$ & 2 & - & 一 & - & - & - & 7 \\
\hline$N$. viridula $\ldots \ldots \ldots \ldots \ldots \ldots$ & - & 1 & - & - & - & 一 & 一 \\
\hline Neidium bitchcockii $\ldots \ldots \ldots \ldots$ & 1 & - & - & - & - & 一 & - \\
\hline$N$. iridis $\ldots \ldots \ldots \ldots \ldots \ldots \ldots$ & - & - & 3 & - & - & - & 1 \\
\hline - var. ampliata ............ & 1 & 1 & 1 & - & - & 1 & - \\
\hline Nitzschia angustata .......... & 1 & - & - & - & - & - & 1 \\
\hline N. denticula var. delognei ........ & 1 & 1 & - & - & - & - & 一 \\
\hline$N$. gracilis $\ldots \ldots \ldots \ldots \ldots \ldots$ & 1 & - & - & - & - & - & - \\
\hline 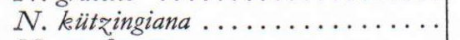 & - & - & 一 & - & - & - & 1 \\
\hline$N$. sp. fragm. $\ldots \ldots \ldots \ldots \ldots \ldots$ & - & - & - & 1 & - & - & - \\
\hline Pinnularia borealis ............ & - & - & - & 1 & - & - & - \\
\hline P. braunii $\ldots \ldots \ldots \ldots \ldots \ldots$ & - & - & - & - & - & - & 2 \\
\hline 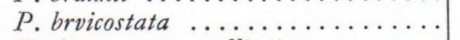 & - & - & - & - & 1 & - & - \\
\hline$P$. divergens var. elliptica ....... & - & - & - & - & - & - & 1 \\
\hline$P$. gentilis $\ldots \ldots \ldots \ldots \ldots \ldots \ldots \ldots \ldots \ldots \ldots \ldots \ldots$ & - & 1 & 2 & - & - & - & - \\
\hline 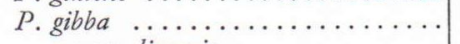 & - & - & - & - & - & 1 & 5 \\
\hline - var. linearis $\quad \ldots \ldots \ldots \ldots \ldots$ & 1 & - & 一 & - & - & - & 3 \\
\hline — var. mesogongyla .......... & - & - & - & - & - & - & 2 \\
\hline 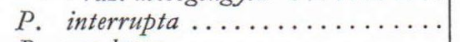 & 1 & 11 & 24 & - & - & - & 4 \\
\hline 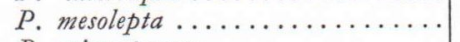 & 一 & 8 & 12 & - & 1 & - & 5 \\
\hline P. microstauron $\ldots \ldots \ldots \ldots \ldots \ldots$ & - & 1 & - & - & - & - & 2 \\
\hline$P$. nobilis $\ldots \ldots \ldots \ldots \ldots \ldots \ldots$ & 一 & - & 1 & - & - & - & 一 \\
\hline 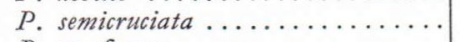 & - & 1 & - & - & - & - & 一 \\
\hline$P$. sp. fragm. $\ldots \ldots \ldots \ldots \ldots \ldots$ & - & 6 & 7 & 1 & - & - & 一 \\
\hline$P$. streptoraphe $\ldots \ldots \ldots \ldots \ldots \ldots$ & - & 一 & 1 & 2 & - & - & 一 \\
\hline$P$. viridis $\ldots \ldots \ldots \ldots \ldots \ldots \ldots$ & - & 4 & 1 & - & - & - & - \\
\hline - var. sudetica ............ & - & 4 & 1 & 1 & 3 & 1 & 2 \\
\hline * Rhabdonema arcuatum .......... & - & - & 一 & - & 1 & - & - \\
\hline Rhopalodia gibba ............ & 1 & 2 & 一 & - & - & - & 3 \\
\hline - var. ventricosa $\ldots \ldots \ldots \ldots$ & 一 & 1 & - & - & - & - & - \\
\hline Strauroneis acuta ............ & - & - & - & 1 & - & - & - \\
\hline 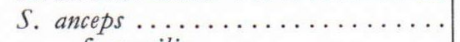 & 1 & 3 & - & - & 2 & 6 & 9 \\
\hline - f. gracilis .............. & 2 & - & 一 & - & - & - & 5 \\
\hline S. obtusa var. lapponica ......... & - & - & - & - & 1 & 2 & - \\
\hline S. phoenicenteron .............. & - & 4 & 20 & 1 & 3 & 6 & 1 \\
\hline S. smitbii $\ldots \ldots \ldots \ldots \ldots \ldots \ldots$ & - & 1 & - & - & - & - & 一 \\
\hline Stephanodiscus astraea var. minutula & 1 & 一 & - & - & - & - & - \\
\hline * Stephanopyxis turris var. polaris & - & - & - & - & - & 2 & 一 \\
\hline Surirella turgida .............. & - & 一 & - & - & - & 6 & - \\
\hline 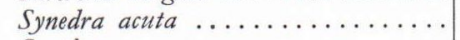 & 1 & 4 & - & - & - & - & - \\
\hline S. ulna $\ldots \ldots \ldots \ldots \ldots \ldots \ldots$ & - & 1 & - & - & - & - & 1 \\
\hline Tabellaria fenestrata ............ & 3 & - & 一 & 一 & - & - & 5 \\
\hline \multirow[t]{2}{*}{ T. flocculosa ............... } & 4 & - & 一 & 一 & 一 & 一 & 2 \\
\hline & 100 & 100 & 100 & 16 & 100 & 100 & 100 \\
\hline
\end{tabular}

Die angetroffenen 16 Exemplare sind Kleinwasserformen bis auf Mastogloia dansei var. streptoraphe, die eine Form leicht salzhaltigen W'assers ist. In dem unmittelbar unterlagerten Schluff kam in einer von Cymbella aspera dominierten Diatomeenflora ein intaktes Exemplar von Rhab- donema arcuatum vor, die eine Salzwasserform ist. Noch weitere $10 \mathrm{~cm}$ tiefer wurde die Salzwasserform Stephanopyxis turris var. polaris in zwei Exemplaren gefunden. Auch an dieser Stelle machte Cymbella aspera die Mehrheit aus. Ganz unten ist die Diatomeenflora des Feinsandes 


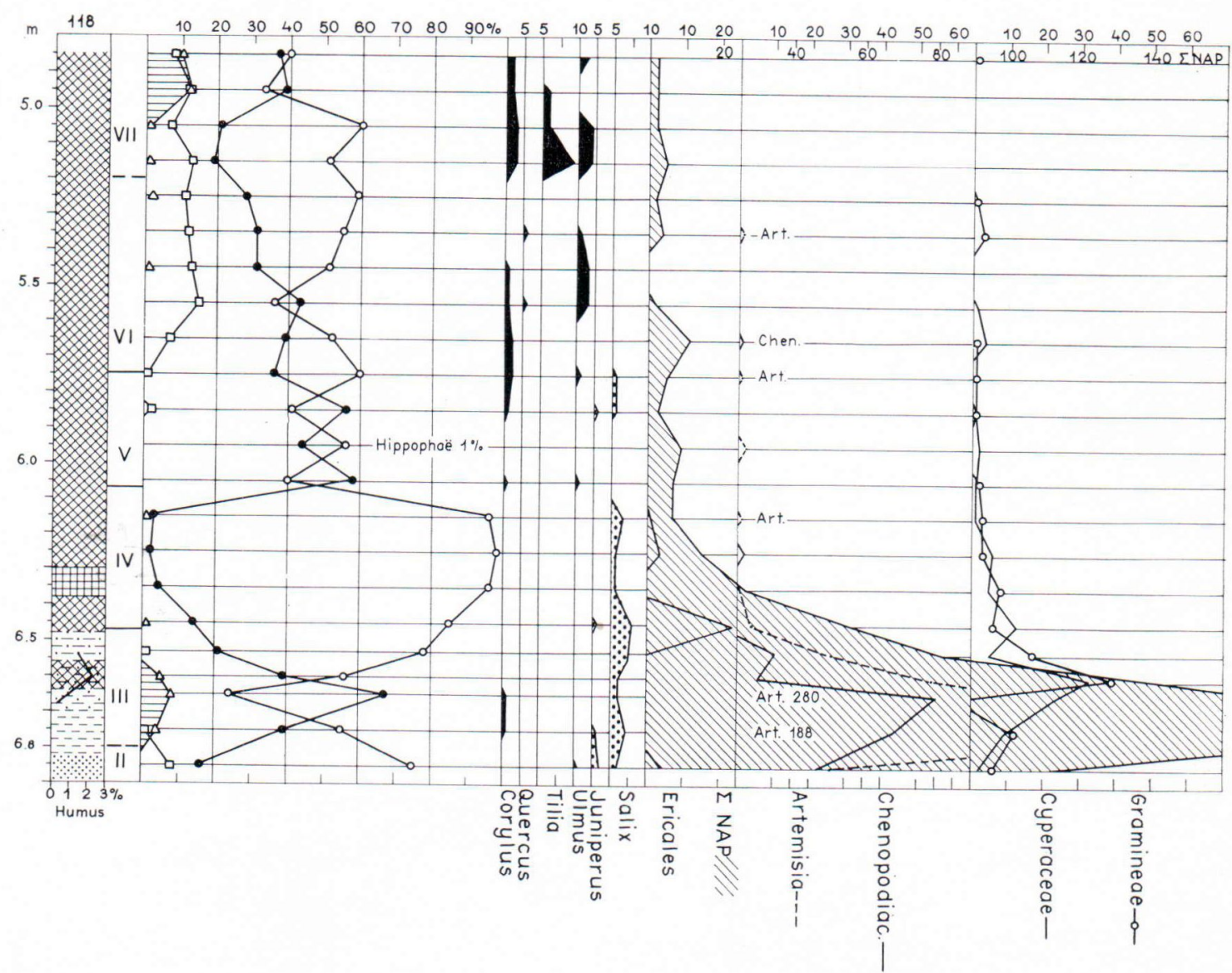

Abb. 17. Pollendiagramm von Sippurilampi.

anders geartet als die vorige, sie umfasst Kleinwasserformen ohne deutliche Maximumarten und ohne Spuren vom Einfluss salzhaltigen Wassers. Auch in der oberhalb von der gyttjahaltigen Zwischenschicht gelegenen Sedimentfolge herrschen die Kleinwasserformen vor.

Zunächst aufgrund der Salzwasserdiatomeen und der homogenen Struktur des Tons hat es den Anschein, dass der spätglaziale Ton vom Sippurilampi (6.8-6.7 m) im Meer abgelagert worden ist. In diesem Fälle wäre der Anteil der marinen Kieselalgen wegen der Trübung des Wassers klein gewesen, und von den einströmenden Schmelzwässern wären vielleicht Diatomeen aus der Spaltenzone des Eisrandes abgesetzt worden. Auch aus den Becken des damaligen Schärenhofes können Kleinwasserformen in die Sedimente geraten sein. Dass die Maximumart, Cymbella aspera, so abgenutzt war, lässt eine Umlagerung vermuten. Aber wenn man andererseits wieder annimmt, die Salzwasserformen seien interglazialer Herkunft, dann ist es merkwürdig, dass dies nicht im alleruntersten Feinsand zu sehen wäre. Die Lage der Salzwasserformen im Ton steht im Einklang auch mit manchen anderen Untersuchungen, nach denen vor dem Baltischen Eissee ein spätglaziales Yoldiameer bestanden haben soll (vgl. Mölder 1944). Die Sediment- und Diatomeensukzession im untersten Abschnitt der Schichtenfolge deutet 
vielleicht auf eine spätglaziale marine Transgression hin, die möglicherweise im ausgehenden Alleröd eingesetzt und ihr Maximum in der Jüngeren Dryaszeit erreicht hätte. Die gleiche Geschehnisreihe ist u.a. in Uusimaa südlich von den Salpausselkäs festgestellt worden (Tynni 1960, 1966).

Nach E. Nilsson (1968) herrschte in der Älteren Dryaszeit eine marine Phase des Baltikums, während wiederum im Alleröd und in der Jüngeren Dryaszeit der Baltische Eissee herrschte.

Im Kirchspiel Ruokolahti $1.5 \mathrm{~km}$ südostwärts vom See Ahjärvi liegt in etwa $126 \mathrm{~m}$ Höhe ein Moor (Abb. 2, Punkt 10), wo eine Probeserie erbohrt wurde. Diese enthielt von 3,6 m Tiefe aufwärts zunächst $10 \mathrm{~cm}$ Schluff, dann $40 \mathrm{~cm}$ Gyttja sowie Seggen- und Sphagnumtorfe. Der Pollendatierung gemäss ist der Schluff in der Jüngeren Dryaszeit abgelagert worden. Die Bildung der Gyttja setzte eingangs der Präborealzeit ein, in welchem Zusammenhang auch Empetrum ein Maximum von $23 \%$ hat. Die Bodensedimente sind der Pollendatierung gemäss nicht so alt wie im Sippurilampi. Auch die Diatomeenflora besteht ausschliesslich aus Kleinseeformen. Die Schichtenfolge entspricht somit der ausklingenden Spätglazialzeit und dem beginnenden Postglazial, als das Niveau des Moores (126 m ü.d.M.) schon vom Baltikum abgeschnürt war.

Das Moor Valkeaneva liegt in der südlichen Partie des Kirchspiels Kitee (Abb. 2, Punkt 11) in ca. $103 \mathrm{~m}$ Höhe am Rand eines Weihers. Die organische Sedimentation hat auch hier gleich anfangs des Präboreals eingesetzt. Zuvor waren in der Spätglazialzeit $40 \mathrm{~cm}$ Schluff und Feinsand abgelagert worden. Als der untere Abschnitt des präborealen Gyttjasediments entstand, lag das Becken im Bereich eines grösseren Gewässers, wofür u.a. das Vorkommen der Grosssee-Plankton-Kieselalge Gyrosigma attenuatum ein Zeichen ist. Früher haben wir in Tohmajärvi in ca. $125 \mathrm{~m}$ Höhe in der präborealen Gyttja des Weihers Suksilampi 11 \% Grosssee-Diatomeen gefunden (op.cit.). Damals glaubten wir, den Befund auf lokale Umstände zurückzuführen zu müssen. Aufgrund der neuen Beobachtung ist es aber nicht ausgeschlossen, dass das Gebiet zu Beginn der Präborealzeit auch in weiterer Ausdehnung vom Wasser überflutet war. Beachtenswert ist es, dass auch in den Lagerfolgen südlich vom 1. Salpausselkä, aus Änkilä, die gleichaltrigen Sedimente Grossseediatomeen enthalten.

Im Kirchspiel Kesälahti wurde in Varmonniemi in ca. $85 \mathrm{~m}$ Höhe (Abb. 2, Punkt 12) in einem üppigen Bruchmoor eine Probeserie erbohrt, in welcher das unterste Sediment homogener, relativ fetter Ton war. Der Pollenanalyse gemäss ist in der oberflächlichen Partie des Tons in der von Pinus (40\%) und Betula (39\%) beherrschten Pollenflora recht reichlich Pollen von edlen Laubbäumen (insgesamt $12 \%$ ) enthalten, und zwar hauptsächlich Tilia $(8 \%)$. Die letztgenannten Mengen sind im Vergleich zur Pollenflora des übergelagerten Sediments ein Vielfaches. Die den Ton bedeckende Torfablagerung ist auch erst gegen Ende der postglazialen Wärmezeit oder danach entstanden. Der Tonboden ist in der Wärmezeit wahrscheinlich Substrat einer üppigen, u.a. Tilia enthaltenden Waldvegetation gewesen, in welches natürlich durch den Einfluss der Witterungsfaktoren Pollen gelangt ist.

Die Diatomeenflora des Tons ist spärlich und von der gleichen Art wie in Kleingewässern oder teilweise auch auf dem Lande. Die maximale Art Hantzschia amphioxys (11 St./43) gedeiht auch auf feuchtem Boden. Der fragliche Artenbestand ist in der Wärmezeit vermutlich auf die gleiche Weise in den Ton gekommen wie auch der Pollen. Als Zeichen vom Einfluss salzigen Wassers ist nur ein Fragment von Coscinodiscus festgestellt worden.

Aufgrund des oben Gesagten lässt sich die Sedimentation von Varmonniemi zeitlich nicht mit Bestimmtheit festlegen, wahrscheinlich ist es aber, dass sie zu Beginn des Präboreals in einem grösseren, vermutlich zum Bereich des Ladogasees gehörigen Gewässer stattgefunden hat. 


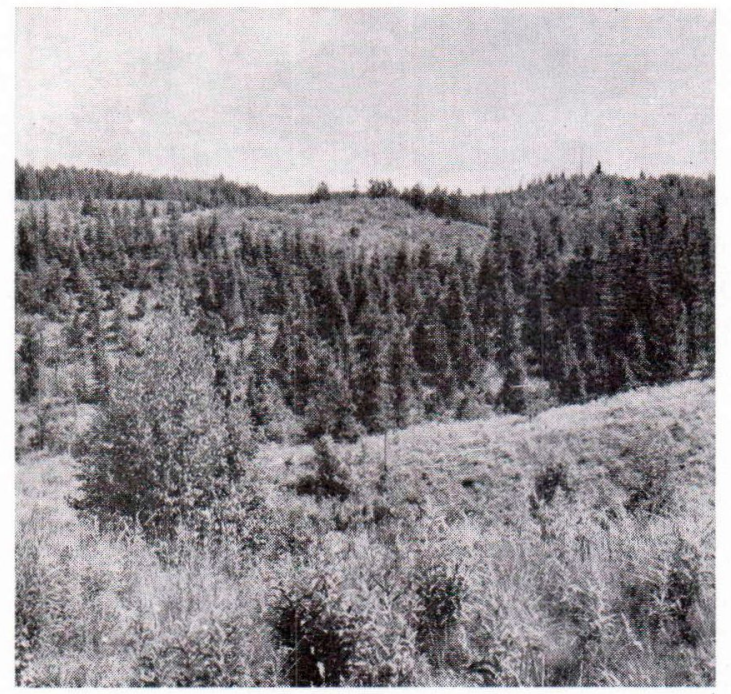

Abb. 18. Grubig-hügeliges Gelände des zweiten Salpausselkä in der Gegend von Kesälahti.

Der See Pikku Torsanjärvi liegt im Kirchspiel Rautjärvi unweit vom Proximalteil des Ersten Salpausselkä im Niveau von $80 \mathrm{~m}$ (Abb. 2, Punkt 13) östlich von relativ hohem Gelände. Die Bodensedimente im Ufermoor des Sees umfassen eine $5 \mathrm{~cm}$ dicke Schluff- und eine ebenfalls $5 \mathrm{~cm}$ dicke Feinsandablagerung. Der Pollenstatistik gemäss sind sie in der Zonengrenze III/IV oder gleich danach entstanden. An diesen Stellen herrscht ein Pinus-Maximum, aber der NBP-Anteil ist relativ klein (Artemisia $11 \%$ ). Weiter oben in der unteren Partie der Gyttja liegt das präboreale Betula-Maximum.

Im Schluff und Ton besteht die Diatomeenflora aus Süsswasserformen, bevorzugt Kleinwasserarten, es sind aber auch in geringerer Zahl Grossseeformen darunter, wie z.B. Cymatopleura elliptica und Cymbella ehrenbergi. Das Fehlen oder spärliche Vorkommen der Planktonformen in den Bodensedimenten war nicht zu erwarten, weil die Sedimentationsstelle zu einem Seebecken gehörte.

\section{Die Zone des Zweiten Salpausselkä}

Der Zweite Salpausselkä läuft im Abstand von ca. $20 \mathrm{~km}$ ungefähr parallel mit dem Ersten Sal- pausselkä. Der vom südwestlichen Teil des Untersuchungsgebiets, von Eräjärvi, nach Vuoriniemi im Nordosten sich erstreckende Abschnitt des Salpausselkä ist nahezu $40 \mathrm{~km}$ lang, ziemlich uneinheitlich und bricht stellenweise ab. Zwischen dem Kirchspiel Punkaharju und Kitee dagegen bildet der Zweite Salpausselkä ein besonders ausgedehntes Akkumulationsgebiet. Der Zweite Salpausselkä liegt in einer Gegend, die durchschnittlich höher ist als die Umgebung. Kennzeichnend für den uneinheitlichen SW-Teil ist insbesondere im proximalen Abschnitt grosse topographische Abwechslung. In vielen Fällen ist diese mannigfaltige Topographie durch den Felsgrund bedingt. Besonders in dem breiten Teil des 2. Salpausselkä liegen die gut ausgebildeten Plateauflächen. U.a. in Kesälahti befindet sich in ca. 104-105 m Höhe ein grosses Plateau (Bestimmung von Leiviskä). Nach Sauramo (1958) entspricht es dem Baltischen Eissee I, während wiederum die niedrigeren Plateaus jüngeren Stadien des Baltischen Eissees entsprechen sollen. Nach Hyyppä (1960) wäre das 104-105 m hohe Plateau älter als der Baltische Eissee und entspräche dem Karelischen Eismeer(oder Eissee-) Stadium 2. Das Niveau des Baltischen Eissees I dagegen läge der genannten Untersuchung gemäss in ca. $95 \mathrm{~m}$ Höhe.

Der höchste Proximalteil des Zweiten Salpausselkä in Kesälahti ist Poronniemi ca. $141 \mathrm{~m}$ ü.d.M. Das Material ist Moräne, aber in ca. $135 \mathrm{~m}$ Höhe liegt eine kleinere Uferböschung. In Kesälahti besteht der Proximalteil des Salpausselkä oberhalb von der Plateaufläche aus Hügel- und Grubengelände (Abb. 18).

Im Kirchspiel Sääminki im Dorf Ruhvana sowie im Kirchspiel Punkaharju in der Gegend von Kalajärvi teilt der Zweite Salpausselkä sich in zwei parallel laufende Rücken (Abb. 1). Im Zwischengelände im Dorf Ruhvana liegt die höchste Stelle, eine moränenartige ebenflächige Kuppe, in ca. $148 \mathrm{~m}$ Höhe.

Im Kirchspiel Kitee im Gebiet von Suorlahti befindet sich in dem etwa $100 \mathrm{~m}$ ü. d. M. Plateau des Zweiten Salpausselkä ein ziemlich grosser 


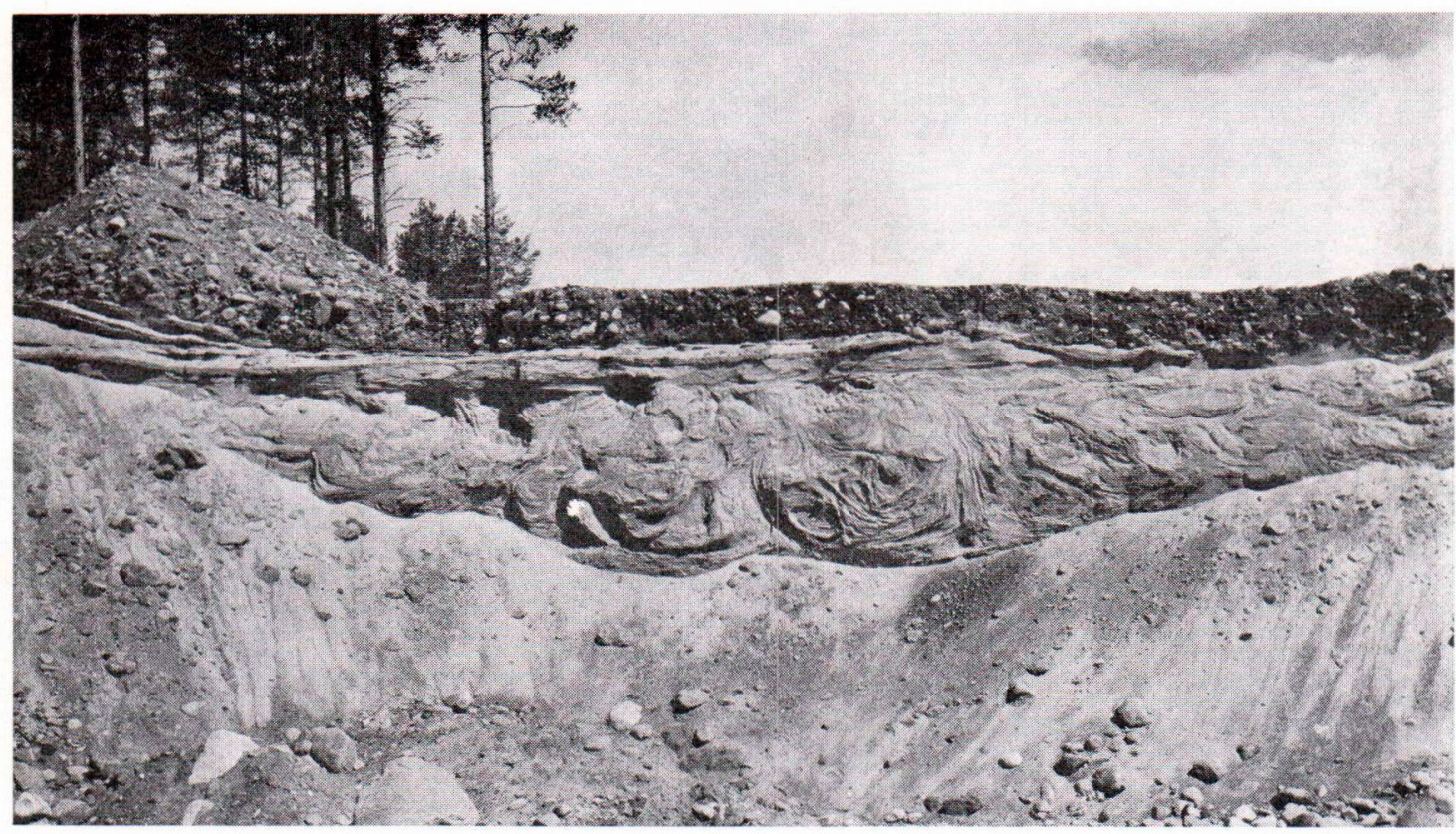

Abb. 19. Aufschluss im Plateau des Zweiten Salpausselkä in Suorlahti. In der Mittelpartie sieht man die Faltstruktur des Feinsandes.

und ca. $10 \mathrm{~m}$ tiefer Bodenaufschluss (Abb. 2 . Punkt 14). Die oberflächliche Partie, ca. $3 \mathrm{~m}$, ist grobes, glazifluviales Material mit vorwiegend Kies, aber unterhalb davon ist das Material nur Feinsand. Im oberen Abschnitt des Feinsandsediments ist eine $2 \mathrm{~m}$ mächtige Faltungszone $z u$ sehen (Abb. 19). Ober- und unterhalb von der letztgenannten Zone ist der Feinsand waagerecht geschichtet. Die Faltung kann möglicherweise im Zusammenhang mit der offenbar recht gewaltsamen Akkumulation der aufliegenden, grobkörnigen Ablagerung zustande gekommen sein.

Im Dorf Kissala in Kesälahti (Abb. 2, Punkt 15), in dem wechselreichen Proximalteil des Zweiten Salpausselkä, liegt typische Moräne auf einer glazifluvialen Ablagerung (Abb. 20). Die Moräne des Salpausselkä ist oftmals sandiger als der gewöhnliche Feinsand-Sand-Moränentyp des Gebiets. Aus Abb. 21 sind die Korngrössen der im Zusammenhang mit den glazifluvialen Bildungen der Salpausselkäs und mit den glazifluvialen Aufschüttungen überhaupt angetroffenen Morä- nenplatten sowie der regelrechten Grundmoräne des Gebiets ersichtlich.

\section{Zwei Moorscbicbtenfolgen}

In Eräjärvi auf der Proximalseite des Zweiten Salpausselkä ist das Gelände ein Fels- und Moränengebiet mit wechselnder Topographie. In ziemlich hohen Gegenden liegen in den Senken kleine Weiher und Moore. Am Ufer eines in ca. $125 \mathrm{~m}$ Höhe gelegenen Weihers (Abb. 2, Punkt 16) wurde eine Schichtenfolge von den groben Grundsedimenten $90 \mathrm{~cm}$ aufwärts erbohrt. Das von dieser Schichtenfolge hergestellte Pollendiagramm beleuchtet die älteste Vegetationsentwicklung der näheren Umgebung (Abb. 22). Ferner konnte mit Hilfe einer $C^{14}$-Analyse die Pollendatierung bestätigt werden. Die fragliche Radiokarbondatierung ist an Bryales-haltigem Feinsand aus ca. $4.4 \mathrm{~m}$ Tiefe gemacht worden. Das Resultat $8150 \pm 400$ v.Chr. zeigt, dass der fragliche, von Pinus beherrschte Horizont 


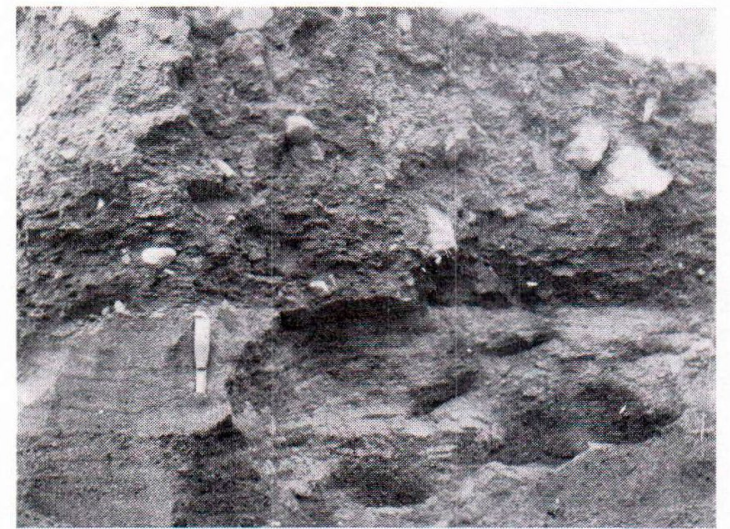

Abb. 20. Aufschluss im Proximalteil des Zweiten Salpausselkä in Kissala, Kesälahti. Eine Moränendecke mit Lamellenstruktur auf glazifluvialem Material.

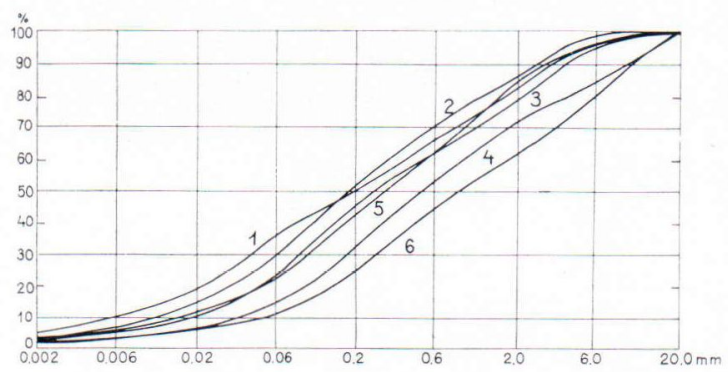

Abb. 21. Korngrössenkurven vom Material der Moränenplatten und der für das Gebiet charakteristischen eigentlichen Grundmoräne. 1. Grundmoräne, Vorfeld des Ersten Salpausselkä, 2. Grundmoräne, Zwischengelände der Salpausselkäs, 3. Grundmoräne, NE-Seite des Zweiten Salpausselkä. 4. Erster Salpausselkä, Koitsanlahti, 5. Aufschluss von Varmonniemi, 6. Zweiter Salpausselkä, Kissala.

etwa in die Zonengrenze III/IV fällt, wie auch die Pollenverhältnisse erkennen lassen. Oberhalb von dem Bryales-haltigen Feinsand ist ein Empetrum-Maximum. In Südfinnland liegt es im allgemeinen ungefähr an der Zonengrenze III/IV oder im oberen Abschnitt der Zone III. Die relativ spärlichen Vorkommen von Artemisia (11 -19 \%) und Chenopodiaceae (4-5\%) hängen vielleicht damit zusammen, dass in dieser Gegend z.Zt. der Sedimentation in der Nähe des Eisrandes verhältnismässig wenig lokale Krautvegetation wuchs. In diesem Falle trat der vom Wind angewehte Pollen, wie Pinus, betont hervor.
Wahrscheinlich aber standen damals doch in der weiteren Umgebung allgemein Kiefern.

Die lokale frühe Vegetationssukzession sieht im Licht der Pollenanalysen folgendermassen aus: Anfänglich in der Jüngeren Dryaszeit war die Vegetation sehr karg; in den feuchten Niederungen wuchsen Bryales-Moose und in der Umgebung zuvörderst Seggen, Gräser und u.a. Rumex. Später, gegen Ende der Jüngeren Dryaszeit breiteten sich Empetrum und Salix aus sowie vielleicht eine schüttere, den Tundren eigene Birkenvegetation, die sich im Präboreal zu Wäldern verdichtete.

Die Verhältnisse z.Zt. der Entstehung der Bodensedimente in dem Ablagerungsbecken sind besonders an den Kieselalgen zu erkennen. In dem ganzen untersuchten Teil treten nur Kleinsüsswasserformen auf (Tabelle 2). In der Bodenpartie in dem Bryales-haltigen Feinsand und in dem unterlagerten Feinsand ist die Individuenzahl ziemlich klein, aber u.a. der das Bryaleshaltige Sediment bedeckende Feinsand enthält schon reichlich Diatomeen. Die vorherrschende Art ist Fragilaria pinnata (56\%), und an zweiter Stelle steht Eunotia praerupta (19\%). Der Diatomeenflora gemäss ist die ganze fragliche Schichtenfolge in einem kleinen Weiher abgelagert worden. Die Bryales-haltige Zwischenschicht geht offenbar nicht auf Schwankungen des Wasserspiegels zurück, sondern wahrscheinlich auf klimatische Faktoren.

Im Kirchspiel Punkaharju, in der Gegend, wo der Zweite Salpausselkä in zwei Züge aufgeteilt ist, wurde im Zwischengelände die Lagerfolge von Myhkyrälampi erbohrt (Abb.2, Punkt 17). Der Weiher Myhkyrälampi liegt ca. $97 \mathrm{~m}$ ü.d. M. Der untersuchte Abschnitt der Schichtenfolge umfasst die Bodensedimente des Ufermoors in einer Tiefe von 4.2-3.3 m. Die Pollenverhältnisse sind ähnlich wie in der vorbeschriebenen Lagerfolge, und das schluffige Bodensediment des Moors ist möglicherweise in der Jüngeren Dryaszeit entstanden. Die Gyttjabildung setzte in der mittleren Präborealzeit ein (von ca. $3.7 \mathrm{~m}$ Tiefe aufwärts). 


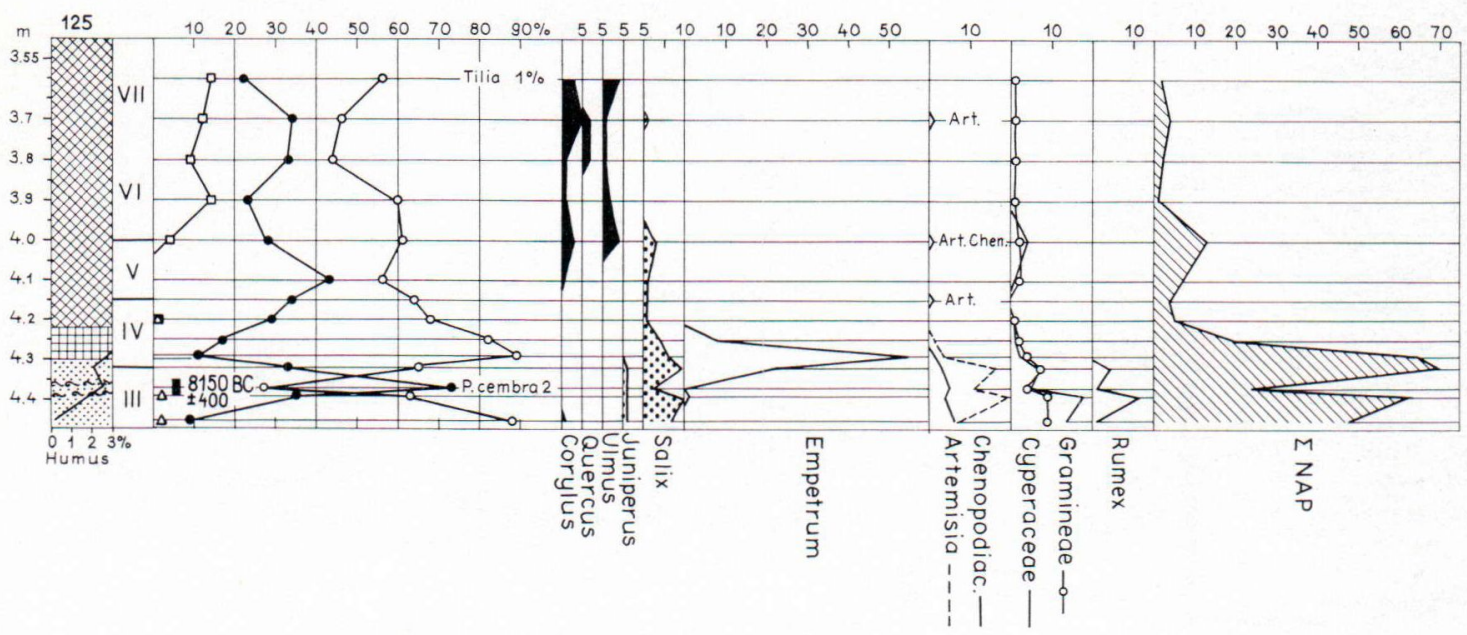

Abb. 22. Pollendiagramm von dem Moorweiher in Eräjärvi.

Die Diatomeenflora ist in den Sedimenten der unteren Partie spärlich und typisch für einen Kleinsee. Weiter oben zeigen ausser den Kleinseeformen einige Planktonarten, u.a. Tabellaria fenestrata, limnische Sedimentation an. Regelrechte Grossseeformen fehlen an der untersuchten Stelle.

\section{Überblick von der spät- und postglazialen Entwicklung des Gebiets}

In dem Untersuchungsgebiet sind aufgrund der Morphologie und der Bodenaufschlüsse der Salpausselkäs die grössten Plateaus des distalen Teils infolge glazifluvialer Tätigkeit zustande gekommen. An den Proximalteil schliessen oft Moränendecken an, die durch Oszillationen des Eisrandes entstanden sind. U.a. an der Verbreitung der glazifluvialen Aufschüttungen kann man sehen, dass die Spalten im Eisrand im allgemeinen der Richtung der Bruchspaltenlinien des Felsgrundes folgen. An den höher gelegenen Stellen im Gelände wich der Eisrand in ziemlich seichtem Wasser zurück, weshalb die von den Eisspalten begrenzten, grossen Eisklötze in situ abschmolzen.
Die genauere Datierung des Eisrückzugs ist noch eine offene Frage. Voraussetzung dafür wäre eine Bändertonchronologie und deren Verknüpfung mit älteren biogenen Ablagerungen. Die ältesten bisher in der Gegend gefundenen, organische Stoffe führenden Ablagerungen haben den $\mathrm{C}^{14}$-Datierungen gemäss folgendes Alter: Ausserhalb des Ersten Salpausselkä $10140 \pm$ 140 J. (Mustalampi; Repo und Tynni 1967), zwischen den Salpausselkäs $10200 \pm 300 \mathrm{~J}$. (Koivusilta) und in der Nähe des Zweiten Salpausselkä, auf der Proximalseite $10100 \pm 400 \mathrm{~J}$. (Ein Moorweiher, Eräjärvi). An den fraglichen Sedimentationsstätten herrscht ein Maximum oder Anstieg des Pinus-Pollens. Im subarktischen Pollenspektrum gilt Zunahme des Pinus-Pollens im allgemeinen für ein Zeichen relativ günstigen Klimas. Die mit der Radiokarbondatierung erhaltenen Alter gehören alle in die gleiche Grössenklasse und entsprechen in der von uns angewandten Pollenzonierung der ausgehenden Jüngeren Dryaszeit. In Mitteleuropa gilt ja für die Grenze zwischen Jüngerer Dryaszeit und Präboreal etwa 8300 v.Chr. Man darf jedoch annehmen, dass in Finnland der Wandel des Klimas von arktisch in subarktisch später als in Mitteleuropa eingetreten ist. 
Tabelle 2.

Diatomeen der Schichtenfolge von einem Weiher nördlich des Sees Eräjärvi

\begin{tabular}{|c|c|c|c|c|c|c|c|c|c|c|c|}
\hline Zone & \multicolumn{2}{|c|}{ VII } & \multicolumn{2}{|c|}{ VI } & \multicolumn{2}{|c|}{$\mathrm{V}$} & \multicolumn{3}{|c|}{ IV } & \multicolumn{2}{|c|}{ III } \\
\hline Tiefe $\mathrm{cm}$ & 360 & 370 & 380 & 390 & 400 & 410 & 420 & 425 & 430 & 435 & 445 \\
\hline Acbnanthes flexella ............. & - & - & - & - & - & - & - & 2 & - & - & - \\
\hline A. minutissima var. cryptocephala .. & - & - & - & - & - & - & 1 & - & - & - & - \\
\hline Amphora ovalis var. libyca ........ & - & - & - & - & - & - & - & 4 & - & - & 一 \\
\hline - var. pediculus ................ & - & - & - & - & - & - & - & - & - & 1 & 2 \\
\hline Anomoeoneis follis ................ & - & - & - & 1 & - & 1 & - & - & - & 一 & - \\
\hline 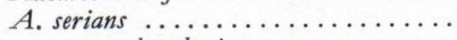 & 一 & - & - & - & 2 & 1 & - & - & - & - & - \\
\hline - var. brachysira $\ldots \ldots \ldots \ldots \ldots$ & 4 & - & - & 1 & - & 1 & - & - & - & - & - \\
\hline 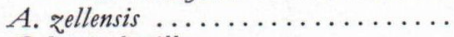 & - & - & - & - & - & - & - & 1 & - & - & - \\
\hline Caloneis bacillum $\ldots \ldots \ldots \ldots \ldots$ & - & - & - & - & - & - & - & 1 & $\overline{1}$ & - & 一 \\
\hline Cymbella affinis $\ldots \ldots \ldots \ldots \ldots \ldots$ & - & - & & - & $\overline{5}_{5}$ & - & - & - & 1 & - & - \\
\hline C. ampbicephala $\ldots \ldots \ldots \ldots \ldots \ldots$ & - & 2 & 3 & - & 5 & $\overline{7}$ & - & - & - & - & - \\
\hline a $\ldots \ldots \ldots \ldots \ldots \ldots$ & $\overline{1}$ & - & $\overline{2}$ & $\overline{6}$ & $-\overline{3}$ & $\begin{array}{l}7 \\
5\end{array}$ & 4 & - & $\overline{1}$ & - & - \\
\hline$\ldots \ldots \ldots \ldots \ldots \ldots \ldots$ & 1 & 4 & 2 & 6 & 3 & 5 & 4 & - & 1 & - & - \\
\hline C. hebridica $\ldots \ldots \ldots \ldots \ldots \ldots \ldots$ & - & 2 & - & 1 & 1 & - & - & - & - & - & - \\
\hline 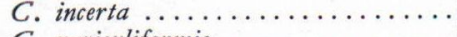 & - & - & $\overline{0}$ & 5 & 1 & - & $\overline{4}$ & $\overline{1}$ & - & - & 1 \\
\hline C. naviculiformis $\ldots \ldots \ldots \ldots \ldots \ldots$ & 2 & 1 & 2 & $\begin{array}{l}2 \\
2\end{array}$ & 1 & - & 4 & 1 & - & - & 一 \\
\hline … & - & - & - & 2 & - & 二 & 二 & 二 & 二 & $\overline{1}$ & $\overline{1}$ \\
\hline$\cdots \cdots \cdots \cdots \cdots$ & $\overline{2}$ & $\overline{1}$ & $\overline{1}$ & $\overline{2}$ & $\overline{2}$ & $\overline{1}$ & 1 & 1 & - & 1 & 1 \\
\hline 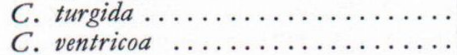 & 2 & 2 & 4 & 5 & 1 & - & - & - & - & 1 & - \\
\hline unis ............. & - & - & - & - & - & - & 1 & - & - & - & - \\
\hline $\operatorname{ex} \ldots \ldots \ldots \ldots \ldots$ & - & - & - & - & - & - & - & 1 & - & - & - \\
\hline$\ldots \ldots \ldots \ldots \ldots \ldots$ & - & 1 & - & 1 & 1 & 1 & - & - & - & - & - \\
\hline — var. bidens $\ldots \ldots \ldots \ldots \ldots$ & - & - & - & - & - & 2 & 1 & - & $=$ & - & - \\
\hline E. diodon $\ldots \ldots \ldots \ldots \ldots \ldots \ldots$ & - & - & - & - & - & - & - & 一 & 2 & - & - \\
\hline$\ldots \ldots \ldots \ldots \ldots \ldots \ldots$ & 1 & - & 2 & 1 & - & - & - & - & - & - & 1 \\
\hline - var. bidens $\ldots \ldots \ldots \ldots \ldots \ldots$ & - & - & - & - & - & 1 & - & - & - & - & - \\
\hline$\ldots \ldots \ldots \ldots \ldots \ldots$ & - & 2 & 3 & - & - & - & - & - & - & - & - \\
\hline E. flexuo & 2 & 2 & 一 & - & - & 1 & - & - & - & - & - \\
\hline E. $j a ̈$ & 1 & 1 & 1 & 1 & 1 & - & - & - & - & - & - \\
\hline E. lunaris var. capitata $\ldots \ldots \ldots \ldots$ & - & - & - & - & 1 & - & - & - & - & - & - \\
\hline … & - & 1 & - & - & - & - & - & - & - & - & - \\
\hline$\ldots \ldots \ldots \ldots \ldots$ & - & - & - & - & - & 1 & - & - & - & - & - \\
\hline is $\ldots \ldots \ldots \ldots \ldots$ & - & - & - & - & - & 1 & - & - & - & - & - \\
\hline inor $\ldots . . . . . .$. & - & 3 & 6 & - & - & - & $\overline{1}$ & - & 3 & 1 & - \\
\hline E. $p$ & - & - & 一 & - & - & - & 1 & 3 & 19 & - & - \\
\hline E. robus & 1 & 4 & 3 & - & - & - & - & - & - & 1 & 一 \\
\hline$-v$ & 1 & 3 & 1 & 1 & - & - & - & - & - & - & - \\
\hline$-v$ & 1 & 2 & 7 & 10 & 2 & 1 & - & - & - & - & - \\
\hline E. se & 1 & 1 & - & - & - & - & - & - & - & - & - \\
\hline E. $s$ & 3 & 3 & - & - & 1 & 1 & - & - & - & - & - \\
\hline E. $t$ & - & - & - & - & - & - & - & - & - & - & 1 \\
\hline E. $v$ & - & - & - & - & 一 & - & - & - & - & - & 1 \\
\hline E. vener & 2 & 1 & 4 & 5 & 2 & 6 & - & - & - & - & - \\
\hline igustata. & - & - & - & - & 2 & - & - & - & - & - & - \\
\hline F. co & 1 & - & - & 一 & - & - & - & - & - & - & - \\
\hline$\ldots \ldots \ldots \ldots \ldots \ldots$ & E & - & - & - & - & - & 1 & 1 & 2 & - & - \\
\hline- & 3 & - & - & - & - & - & - & - & $\bar{z}$ & - & - \\
\hline F. pin & 1 & - & - & - & - & - & 8 & 11 & 56 & - & - \\
\hline & - & - & - & - & $\overline{0}$ & - & - & 1 & - & - & - \\
\hline homboides & - & 1 & 1 & 3 & 17 & 4 & - & - & 1 & - & - \\
\hline 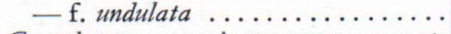 & - & - & - & 一 & - & 1 & - & - & - & - & - \\
\hline acuminatum var. coronata & - & - & - & - & 1 & - & 1 & - & - & - & - \\
\hline eribaud & - & - & $\overline{2}$ & 二 & & 1 & $\overline{2}$ & - & - & - & 二 \\
\hline $\begin{array}{l}\text { statum } \\
\text { trictum }\end{array}$ & 1 & _ & 1 & 二 & - & - & - & - & $\overline{1}$ & 二 & - \\
\hline $\begin{array}{l}\text { G. constrictum } \ldots \\
G \text {. gracile } \ldots \ldots\end{array}$ & - & 2 & 1 & 2 & - & - & - & - & - & - & 一 \\
\hline G. longiceps $\ldots . . .$. . & - & - & - & - & - & - & - & - & 1 & 一 & 一 \\
\hline - var. subclavata . . . . . . . . . & - & - & - & - & 一 & - & - & - & 1 & - & - \\
\hline
\end{tabular}


TABelle 2. (Fortsetzung)

\begin{tabular}{|c|c|c|c|c|c|c|c|c|c|c|c|}
\hline Zone & \multicolumn{2}{|c|}{ VII } & \multicolumn{2}{|c|}{ VI } & \multicolumn{2}{|c|}{ V } & \multicolumn{3}{|c|}{ IV } & \multicolumn{2}{|c|}{ III } \\
\hline Tiefe $\mathrm{cm}$ & 360 & 370 & 380 & 390 & 400 & 410 & 420 & 425 & 430 & 435 & 445 \\
\hline 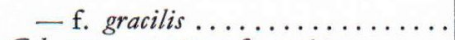 & 一 & - & 一 & 1 & 2 & - & - & - & - & - & - \\
\hline G.l. var. montana f. suecica....... & - & 一 & - & - & - & 一 & 一 & 1 & - & - & 一 \\
\hline G. sphaerophorum ............ & - & 1 & 1 & 1 & 一 & 一 & 一 & - & - & - & 一 \\
\hline Hantrschia ampbioxys ........... & 一 & - & - & - & - & - & - & 一 & 一 & 1 & 1 \\
\hline$H$. elongata $\ldots \ldots \ldots \ldots \ldots \ldots$ & - & 2 & - & 2 & 1 & - & - & - & - & - & - \\
\hline Melosira ambigua $\ldots \ldots \ldots \ldots \ldots$ & - & - & 1 & - & 一 & - & - & - & - & - & - \\
\hline$M$. distans $\ldots \ldots \ldots \ldots \ldots \ldots$ & 5 & 9 & 9 & 4 & 一 & 1 & 一 & 一 & - & - & 一 \\
\hline - var. lirata $\ldots \ldots \ldots \ldots \ldots$ & 8 & - & 1 & 1 & 一 & - & - & - & - & 3 & 一 \\
\hline M. italica ............... & 2 & - & - & - & 一 & - & 一 & - & 一 & 一 & 一 \\
\hline - ssp. subarctica ........... & 2 & 2 & 1 & 1 & - & - & 一 & - & 一 & - & - \\
\hline Navicula cryptocephala ............ & - & - & 一 & - & 1 & - & 1 & - & - & 一 & - \\
\hline N. cuspidata $\ldots \ldots \ldots \ldots \ldots \ldots$ & - & 一 & 一 & - & 一 & 一 & - & 2 & - & - & - \\
\hline N. pupula $\ldots \ldots \ldots \ldots \ldots \ldots$ & 1 & - & - & - & - & - & 2 & 一 & - & - & - \\
\hline - var. rectangularis ........... & 1 & 1 & 1 & 2 & 1 & 1 & 3 & 2 & 1 & - & - \\
\hline N. radiosa ................... & 3 & - & - & - & 3 & 1 & - & 4 & 1 & 一 & 1 \\
\hline - var. tenella ............... & - & 2 & 1 & - & 一 & 8 & 一 & 一 & 一 & - & - \\
\hline N. rbynbocosepbala .............. & 一 & - & - & - & 1 & - & 一 & 一 & - & 一 & - \\
\hline N. subtilissima $\ldots \ldots \ldots \ldots \ldots \ldots$ & 一 & - & 1 & 1 & 1 & 5 & 2 & 一 & - & - & - \\
\hline N. viridula $\ldots \ldots \ldots \ldots \ldots \ldots \ldots$ & 一 & - & - & - & - & - & 一 & 1 & - & 一 & - \\
\hline Neidium affine var. longiceps ....... & 一 & - & 一 & 一 & 1 & - & 一 & - & - & 一 & - \\
\hline N. bitcbcockii ................ & - & - & - & - & - & - & - & 1 & - & - & - \\
\hline N. iridis $\ldots \ldots \ldots \ldots \ldots \ldots \ldots \ldots$ & 1 & 1 & - & 2 & 1 & 2 & 1 & - & - & 一 & - \\
\hline - var. ampliata ............ & 2 & 11 & 5 & 1 & 2 & 4 & 2 & 1 & - & - & - \\
\hline Nitzscbia angustata $\ldots \ldots \ldots \ldots$ & - & - & 一 & - & 一 & - & 1 & 3 & - & - & - \\
\hline N. denticula $\ldots \ldots \ldots \ldots \ldots \ldots$ & - & - & - & - & 一 & - & - & - & 2 & 一 & - \\
\hline N. dissipata $\ldots \ldots \ldots \ldots \ldots \ldots$ & - & - & - & 一 & 一 & 1 & - & 一 & - & - & - \\
\hline N. fonticola ............... & - & - & - & - & 1 & - & 2 & - & - & - & - \\
\hline$N$. kiutzingiana $\ldots \ldots \ldots \ldots \ldots$ & 1 & - & - & - & - & - & - & - & - & - & - \\
\hline$N . \operatorname{recta} \ldots \ldots \ldots \ldots \ldots \ldots \ldots$ & 1 & - & 一 & - & 一 & - & 一 & - & - & - & 一 \\
\hline$N$. sp. fragm. ............ & - & - & 一 & - & - & 一 & - & 一 & - & 1 & - \\
\hline Peronia beribaudi ............. & - & - & - & - & - & 2 & - & - & - & - & 一 \\
\hline Pinnularia braunii ............ & 1 & - & - & - & - & - & - & - & - & - & 一 \\
\hline P. brevicostata ............. & 4 & - & 3 & 4 & 1 & 3 & 一 & - & - & - & - \\
\hline$P$. dactylus ................ & - & - & - & - & - & - & - & - & - & 7 & - \\
\hline 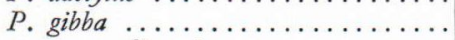 & 3 & 6 & 4 & 5 & 3 & 5 & 4 & - & - & 2 & 3 \\
\hline 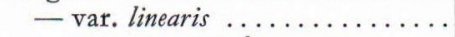 & 1 & 3 & 3 & 4 & 1 & 2 & 3 & 一 & 1 & 1 & - \\
\hline — var. mesogongyla .......... & 1 & - & - & - & - & 一 & - & 1 & - & - & - \\
\hline 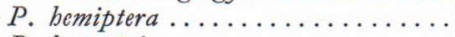 & - & - & - & - & 1 & - & 一 & - & - & - & - \\
\hline P. byyppäei ............... & - & - & - & - & - & - & - & 1 & - & - & - \\
\hline P. interrupta $\ldots \ldots \ldots \ldots \ldots \ldots$ & 12 & 9 & 9 & 5 & 17 & 3 & 2 & 5 & 一 & 1 & - \\
\hline 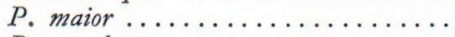 & 一 & - & - & - & 3 & 一 & - & - & - & - & - \\
\hline P. mesolepta ................ & 1 & - & 1 & 1 & 1 & 1 & 3 & 14 & 2 & 一 & - \\
\hline P. microstauron ............. & 2 & - & 一 & 1 & - & 一 & - & 一 & - & - & - \\
\hline 一f. diminutula $\ldots \ldots \ldots \ldots$ & - & - & 一 & - & - & - & 一 & 2 & - & - & - \\
\hline — var. brebissoni ........... & 3 & - & - & - & - & 一 & 一 & 一 & - & - & 一 \\
\hline P. nobilis $\ldots \ldots \ldots \ldots \ldots \ldots \ldots$ & - & - & 一 & - & - & - & 1 & 一 & 1 & 21 & 6 \\
\hline$P$. sp. fragm. $\ldots \ldots \ldots \ldots \ldots \ldots$ & - & - & 一 & - & 一 & - & 一 & 一 & - & 26 & 9 \\
\hline P. streptorapbe $\ldots \ldots \ldots \ldots \ldots \ldots$ & - & - & - & - & - & 一 & - & 一 & - & - & 2 \\
\hline P. viridis $\ldots \ldots \ldots \ldots \ldots \ldots \ldots$ & 一 & - & - & - & - & 一 & 1 & 1 & - & 4 & 14 \\
\hline — var. sudetica . . . . . . . . & 一 & - & - & - & - & - & - & - & - & 1 & - \\
\hline Stauroneis anceps $\ldots \ldots \ldots \ldots \ldots$ & 5 & 3 & 2 & 4 & 2 & 7 & 10 & 23 & 3 & 1 & - \\
\hline 一f. gracilis .............. & 4 & 3 & 3 & 3 & 1 & 3 & 11 & - & - & 一 & - \\
\hline S. obtusa var. lapponica ......... & - & - & 一 & - & 一 & 一 & - & - & - & - & 1 \\
\hline 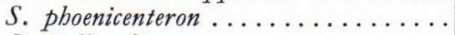 & 2 & 2 & 7 & 4 & 5 & 1 & 1 & 1 & - & 4 & 一 \\
\hline Surirella elegans $\ldots \ldots \ldots \ldots \ldots \ldots$ & - & - & - & 一 & 一 & - & - & 1 & 一 & - & - \\
\hline S. ovata var. pinnata ............ & - & - & 一 & - & - & - & - & - & - & - & 1 \\
\hline Tabellaria fenestrata ............. & 2 & 1 & 一 & 5 & 2 & 6 & 7 & 2 & 1 & - & 一 \\
\hline 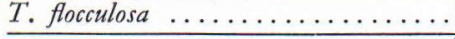 & 2 & 3 & 3 & 4 & 3 & 5 & 14 & 7 & - & - & - \\
\hline & 100 & 100 & 100 & 100 & 100 & 100 & 100 & 100 & 100 & 78 & 45 \\
\hline
\end{tabular}


Nach in Mitteleuropa durchgeführten Untersuchungen zerfällt die um 8300 v. Chr. beginnende Präborealzeit klimatisch in drei Phasen. Die mittlere wäre nach Zoller (1960) in der südlichen Schweiz eine relativ kalte Periode gewesen, nach der $C^{14}$-Datierung 8100-7700 v.Chr. (Piottino-Oszillation). Behre (1967) hat in NWDeutschland in Ost-Friesland festgestellt, dass das Präboreal in drei Teile zerfällt. Der älteste Abschnitt ist relativ günstig, und in der Pollenflora ist er durch Zunahme von Pinus gekennzeichnet. Er fällt in die Zeit von ca. 8300-8100 v.Chr., und Behre hat ihn vorläufig als Friesland-Oszillation bezeichnet, die vor der kalten Piottino-Oszillation geherrscht haben soll. Die jüngste Phase, $7700-6800$ v.Chr., entspricht nach Behre (op.cit.) der endgültigen Klimaverbesserung. Die Dreigeteiltheit des Präboreals soll nach Behre u.a. auch in der Nähe von Hamburg wahrzunehmen sein.

Die organische Stoffe führenden Zwischensedimente von Südost-Finnland entsprechen der
$\mathrm{C}^{14}$-Datierungen gemäss (ca. 8200 v.Chr.) der in Mitteleuropa festgestellten, klimatisch günstigen Friesland-Oszillation (8300-8100 v.Chr.), aber wegen ihrer nördlicheren Lage macht sie sich nur als karge Moosvegetation geltend. Ihre Gleichzeitigkeit in ausgedehnten Gebieten ist am Pinus-Pollen erkenntlich, der in der Pollenflora waldloser Gegenden als Ferntransportpollen betont zum Vorschein kommt.

Den $\mathrm{C}^{14}$-Datierungen gemäss sind die organische Stoffe führenden Feinsandschichten in Südost-Finnland etwas jünger als der Eisrandrückzug von den Randmoränen Mittel-Schwedens. Aufgrund der Öffnung der Billinger Pforte und des Durchbruchs des Baltischen Eissees wird der letztere auf 8213 v.Chr. datiert (E. Nilsson 1968). Die in Südost-Finnland in der Salpausselkä-Zone nach der Radiokarbonmethode datierten Ablagerungen liegen jedoch höher als die Plateaus der Salpausselkäs, und das Abfliessen des Eissees hätte sie somit nicht beeinflussen sollen.

Für die Übersetzung des Textes danken wir Frau Marianne Kahanpää.

\section{LITERATURVERZEICHNIS}

Behre, K.-E. (1967) The Late Glacial and Early Postglacial history of vegetation and climate in Northwestern Germany. Review of Paleobotany and Palynology.

Ber GHell, H. (1903) D 2 Savonlinna, Nyslott; 1 : 400000 (Bodenkarte). Geologinen Toimisto. Helsinki.

- (1904) Geologisk öfversiktskarta öfver Finland. Sektionen D 2. Nyslott. Beskrifning till jordartskartan. Geologiska Kommissionen. Helsingfors.

Donner, J. J., V. Lappalainen and R. G. West (1968) Ice wedges in south-eastern Finland. Geol. Fören. Förh. Bd. 90.

HARDER, R. (1948) Eine Liste deutscher Erddiatomeen. Nachrichten d. Akad. d. Wissensch. in Göttingen, Math.-Phys. Klasse 1948, Hf. 1.

HellaAkoski, A. (1922) Suursaimaa. Referat: GrossSaimaa. Fennia 43. 4.

HYYPPÄ, E. (1963) On the late-Quaternary history of the Baltic Sea. Fennia 89. 1.
- (1966) The late-Quaternary land uplift in the raised and tilted shore levels. Ann. Acad. Sci. Fennicae. A. III. 90 .

Ignatrus, H. (1958) On the rate of sedimentation in the Baltic Sea. C. R. Soc. Géol. Finlande 30.

LeIviskä, I. (1920) Der Salpausselkä. Fennia 41.

Lund, J. W. (1945) Observations on soil Algae. I. The ecology, size and taxonomy of British soil diatoms. The New Phytologist, Vol. 44, N:o 2.

Mölder, K. (1944) Das Karelische Eismeer im Lichte der fossilen Diatomeenfunde. Bull. Comm. géol. Finlande 132.

Nrlsson, E. (1968) Södra Sveriges senkvartära historia. The late-Quaternary history of Southern Sweden. K.V.A. Handl. 12: 1.

REPO, R. (1954) Om förhållandet mellan räfflor och åsar. Geologi N:o 5, 1954.

- (1957) Untersuchungen über die Bewegungen des Inlandeises in Nordkarelien. Bull. Comm. géol. Finlande 179. 
Repo, R. und R. Tynni (1967) Zur spät- und postglazialen Entwicklung im Ostteil des Ersten Salpausselkä. C. R. Soc. Finland 39. géol.

Sauramo, M. (1923) Studies on the Quaternary Varve Sediments in Southern Finland. Bull. Comm. géol. Finlande 60.

- (1958) Die Geschichte der Ostsee. Ann. Acac. Scient. Fennicae, Ser. A, III, 51.

TrnnI, R. (1960) Ostseestadium während der Allerödzeit in Askola, Ost-Uusimaa (Südfinnland). C. R. Soc. Géol. Finlande 32. Bull. Comm. géol. Finlande 188.
- (1966) Über spät- und postglaziale Uferverschiebung in der Gegend von Askola, Südfinnland. Bull. Comm. géol. Finlande 223.

Zoller, H. (1960) Pollenanalytische Untersuchungen zur Vegetationsgeschichte der insubrischen Schweiz. Denkschr. Schweiz. Naturforsch. Ges., Band 83, Abh. 2.

Manuskript eingegangen am 31. Januar 1969. 